\title{
Life cycle and early development of the thecosomatous pteropod Limacina retroversa in the Gulf of Maine, including the effect of elevated $\mathrm{CO}_{2}$ levels
}

Ali A. Thabet ${ }^{\mathrm{ab}}$, Amy E. Maas ${ }^{\mathrm{ac} *}$, Gareth L. Lawson ${ }^{\mathrm{a}}$ and Ann M. Tarrant ${ }^{\mathrm{a}}$

\author{
a. Biology Department, Woods Hole Oceanographic Institution, Woods Hole, MA \\ 02543 \\ b. Zoology Dept., Faculty of Science, Al-Azhar University in Assiut, Assiut, Egypt. \\ c. Bermuda Institute of Ocean Sciences, St. George's GE01, Bermuda \\ *Corresponding Author, equal contribution with lead author \\ Email: amy.maas@bios.edu
}

Phone: 441-297-1880 x131

Keywords: mollusc, ocean acidification, calcification, mortality, developmental delay 


\begin{abstract}
Thecosome pteropods are pelagic molluscs with aragonitic shells. They are considered to be especially vulnerable among plankton to ocean acidification (OA), but to recognize changes due to anthropogenic forcing a baseline understanding of their life history is needed. In the present study, adult Limacina retroversa were collected on five cruises from multiple sites in the Gulf of Maine (between $42^{\circ} 22.1^{\prime}-42^{\circ} 0.0^{\prime} \mathrm{N}$ and $69^{\circ} 42.6^{\prime}-70^{\circ} 15.4^{\prime} \mathrm{W}$; water depths of ca. 45-260 m) from October 2013-November 2014. They were maintained in the laboratory under continuous light at $8^{\circ} \mathrm{C}$. There was evidence of year-round reproduction and an individual life span in the laboratory of 6 months. Eggs laid in captivity were observed throughout development. Hatching occurred after 3 days, the veliger stage was reached after 6-7 days, and metamorphosis to the juvenile stage was after $\sim 1$ month. Reproductive individuals were first observed after 3 months. Calcein staining of embryos revealed calcium storage beginning in the late gastrula stage. Staining was observed in the shell gland, shell field, mantle, and shell margin in later stages. Exposure of two batches of larvae at the gastrula stage to elevated $\mathrm{CO}_{2}$ levels (800 and 1200 ppm) resulted in significantly increased mortality in comparison with individuals raised under ambient ( $400 \mathrm{ppm})$ conditions and a developmental delay in the $1200 \mathrm{ppm}$ treatment compared with the ambient and 800 ppm treatments.
\end{abstract}

\title{
Introduction
}

Pteropods are free-swimming molluscs with a holoplanktonic life-style that are also known as sea butterflies. The thecosome (shelled) pteropods have been the subject of recent research interest because they produce aragonitic shells that are particularly susceptible to ocean acidification (OA) (Comeau et al. 2010a; Lischka et al. 2011; Bednaršek et al. 2012a; Manno et al. 2012). Thecosome pteropods can be found at most depths of the ocean, but are especially abundant in the epipelagic layer. Despite growing interest in this group, multiple aspects of their basic ecology, such as global distribution and life history patterns, remain poorly resolved (Fabry et al. 2008; Hunt et al. 2008; Bednaršek et al. 2012b). Because pteropods may serve as sentinels for the effects of OA, it is important to have a baseline understanding of their ecology, 
developmental timing and life history so that changes due to anthropogenic forcing can be recognized.

For non-photosynthetic calcifying organisms, biological sensitivity to OA results from decreases in carbonate ion concentration, which reduces the availability of this building block for biogenic calcium carbonate structures (Millero 2007). In addition, increases in hydrogen ion concentration reduce the $\mathrm{pH}$, influencing many physiological processes (Fabry et al. 2008; Pörtner 2008). OA has been shown to have deleterious impacts on diverse groups of marine calcifying invertebrates (reviewed by Hendriks et al. 2010; Kroeker et al. 2010). Although the consequences of OA vary among groups, generally it has been found that early life stages, when individuals typically have less energetic reserves to cope with environmental stress, tend to be most sensitive (e.g., Dupont et al. 2008; Kurihara 2008; Albright 2011; Cripps et al. 2014). This is compounded by the fact that the initial sites of calcification tend to be more prone to effects of acidification, likely because they are comprised of more soluble forms of calcium carbonate, are accreted at a rapid rate, and are constrained by a limited energy budget (e.g., Waldbusser et al. 2013; White et al. 2013; Waldbusser et al. 2015b).

To enable studies of the effects of ocean acidification and other stressors on development and early shell formation in thecosome pteropods the normal developmental processes of this group must be clearly documented. The majority of OA work with pteropods has focused on one family within the thecosomes, the Limacinidae. This group is the most numerically dominant in all ocean basins, has a particularly high biomass in polar regions, and has already been shown to be affected by regions of undersaturation (Bednaršek et al. 2012a; Bednaršek et al. 2014).

Most species of Limacinidae appear to share similar reproductive biology, behavior, and larval development (Lalli and Wells 1978; Lalli and Gilmer 1989), and all are protandrous hermaphrodites (starting life as males and developing female gonads as they age). Thus, gender in Limacinidae varies with size, and three types can be identified: small individuals are typically sexually undifferentiated, somewhat larger individuals are solely males, and the largest are simultaneous hermaphrodites (Hsiao 1939). Previous work on the genus Limacina has suggested that some species spawn multiple times per year (Dadon and Cidre 1992), although these authors 
suggest that this is a consequence of asynchrony between two cohorts, with adult mortality after each reproductive event. It has been suggested that polar species may have a 1-2 year life span (Kobayashi 1974; Gannefors et al. 2005; Hunt et al. 2008; Wang 2014), but the life span of temperate and tropical species is unknown and likely shorter. All of these studies have relied upon field sampling to infer life span and reproductive timing because keeping pteropods in captivity has proven difficult (reviewed by Howes et al. 2014).

Relatively little is known regarding the morphology and timing of progression through early developmental stages and initial calcification in the genus Limacina (Lalli and Gilmer 1989). All three of the Limacina spp. studied to date produce egg masses that develop through a trochophore stage into planktotrophic veligers (Lebour 1932; Paranjape 1968; Bandel and Hemleben 1995). Lebour (1932), the first to document early thecosome development, worked with Limacina retroversa, a temperate and sub-polar species. Her findings were based on observations of larvae and juveniles obtained from net tows and of egg masses laid in the laboratory by adults. She observed that the embryonic stages hatched to unshelled larvae on the second day after spawning and developed into veligers with a cup-shaped shell a few days later. In contrast, Paranjape (1968) observed that embryos of the polar species Limacina helicina developed a cup-shaped shell while still in the egg capsule and hatched at the veliger larval stage. Bandel and Hemleben (1995) documented the early development and metamorphosis of the tropical Limacina trochiformis, noting that the sinistrally shelled larvae of this species hatch from the egg capsule after about $2 \mathrm{~d}$ in the veliger stage. Temperatures were not reported by Bandel and Hemleben (1995) or Lebour (1932), making direct comparisons of developmental rates difficult.

Limacina retroversa is a temperate and boreal pteropod that was chosen for this study as a useful model for thecosome life history and development. This species, which is abundant in the North Atlantic and is consistently found in the Gulf of Maine (Redfield 1939) is a characteristic component of the permanent pelagic community, where it can be found throughout the year and is thought to be an important prey item for planktivorous fishes, such as mackerel (Bigelow 1924). Redfield (1939) sampled the seasonal distribution of L. retroversa in the Gulf of Maine and observed that the population density was low during the fall, increased in December, 
and spread westward during the winter. The population of L. retroversa was originally thought to sustain itself with local reproduction (Bigelow 1924), but Redfield (1939) suggested that large numbers of $L$. retroversa are advected into the Gulf of Maine from off-shelf regions rather than produced endemically.

To better characterize the life history and early development of the Limacinidae, we have focused on this easy-to-obtain species, L. retroversa. In the present study, we take advantage of seasonal sampling and have developed a laboratory culture protocol to (1) estimate the generation time, (2) describe the morphology and timing of embryonic and larval developmental stages of $L$. retroversa under constant laboratory conditions, (3) visualize early shell formation, and (4) explore the effects of elevated $\mathrm{CO}_{2}$ on early development.

\section{Materials and methods}

Adult collection and spawning

To observe seasonality in spawning behavior and to obtain fertilized eggs for developmental studies, adult Limacina retroversa were collected from multiple sites in the Gulf of Maine (station locations in the vicinity of $42^{\circ} 22.1^{\prime}-42^{\circ} 0.0^{\prime} \mathrm{N}$ and $69^{\circ} 42.6^{\prime}-70^{\circ} 15.4^{\prime} \mathrm{W}$; water depths of ca. 45-260 m) during 1-3 d cruises beginning October $21^{\text {st }} 2013$, January $29^{\text {th }} 2014$, April $25^{\text {th }} 2014$, August $19^{\text {th }} 2014$ and November $4^{\text {th }} 2014$ on the R/V Tioga. Individuals were sampled via oblique tows of a Reeve net with $333-\mu \mathrm{m}$ mesh. Seawater was collected for $\mathrm{CO}_{2}$ exposure experiments from ca. $30 \mathrm{~m}$ depth using a submersible pump and filtered through $63-\mu \mathrm{m}$ mesh. Aboard ship, adult pteropods were stored in this filtered in situ water (salinity 32-34, depending on the season) in 1 - $\mathrm{L}$ jars that were held in an $8 \pm 1{ }^{\circ} \mathrm{C}$ refrigerator to replicate typical conditions at 50-100 m depth within the study area, where adults were typically found. Additional seawater was transported to a laboratory holding tank and continuously circulated through a $1-\mu \mathrm{m}$ filter. The pteropods were transported to the lab from the vessel via coolers with ice packs to minimize thermal stress.

\section{Pteropod culture}

Juvenile and adult $L$. retroversa were maintained in $13-\mathrm{L}$ glass carboys at $8^{\circ} \mathrm{C}$ in a continuously illuminated climate-controlled room. Since the vertical migratory behavior and light regime in 
the wild is unknown, and although continuous light is not the environment L. retroversa would typically experience in the Gulf of Maine, it was chosen for simplicity and to provide maximum phytoplankton (food) production in the cultures. Adults were fed weekly with 1500-4000 cells $\mathrm{mL}^{-1}$ of Rhodomonas lens and 150-500 cells $\mathrm{mL}^{-1}$ of Heterocapsa triquetra (depending on pteropod density, which ranged from 50-500 individuals per carboy as mortality occurred). The culture water was changed with local 1- $\mu \mathrm{m}$ filtered seawater (inflow from Buzzards Bay, Massachusetts; salinity 31-34) weekly. During each water change, the culture was examined for egg production by gently siphoning the carboys onto a $35-\mu \mathrm{m}$ mesh. The individuals were then transferred to a glass dish and examined under a stereomicroscope. At this time dead pteropods were removed. Fertilized eggs were separated from adults by passing them through a larger mesh net $(>150 \mu \mathrm{m})$, after which eggs and adults were rinsed into separate clean culture vessels.

Early stage embryos and veligers were kept at $8^{\circ} \mathrm{C}$ in 2-L polycarbonate bottles and were fed weekly with 50-500 cells $\mathrm{mL}^{-1}$ of Rhodomonas lens, and Isochrysis sp., clone T-Iso. The number of individuals per bottle ranged from $~ 1000$ at initial collection to $\sim 500$ by the second water change, and dwindled to 100 as mortality occurred. Similar to the adults, their water was changed with local 1- $\mu \mathrm{m}$ filtered seawater (salinity $31-34$ ) weekly by slowly siphoning individuals onto a 35- $\mu \mathrm{m}$ mesh net, briefly observing the individuals under a stereomicroscope, and gently washing them into a freshly cleaned and filled polycarbonate bottle. As the veligers grew larger, the dinoflagellate Heterocapsa triquetra was added to their diet at densities of 50 cells $\mathrm{mL}^{-1}$, their ration of Rhodomonas lens, and Isochrysis sp. clone T-Iso was gradually increased to 2000 cells $\mathrm{mL}^{-1}$, and they were transferred to 13 -L glass carboys.

\section{Developmental observations}

After the April 2014 cruise, a large portion of the first batch of sampled embryos were isolated for studies to characterize the developmental timing of L. retroversa. After initial collection egg capsules and developing pteropods were transferred into crystallization dishes containing $0.2-\mu \mathrm{m}$ filtered in situ seawater (34) and reared at $8{ }^{\circ} \mathrm{C}$. Egg capsules and developing pteropods were collected on mesh nets (35-75 $\mu \mathrm{m}$, depending on the size of the stage) and then rinsed through larger mesh nets $(150 \mu \mathrm{m})$ to remove debris. Swimming gastrulae and trochophores were 
separated from unhatched egg capsules under a stereomicroscope with a Pasteur pipette into clean dishes.

Embryonic and larval pteropods were monitored over $7 \mathrm{~d}$ using a stereomicroscope. To examine the timing of early embryonic development, an egg mass was closely monitored every hour from deposition to the 16-cell stage. For additional observations of larval development, groups of 20 early-stage embryos (1- to 4 -cell stage $; \leq 6 \mathrm{~h}$ old) were collected from gelatinous egg masses into 20-ml glass scintillation vials. Two replicate vials were monitored at 8, 16, 24, 36,48 and $72 \mathrm{~h}$. To observe later developmental stages (trochophore through veliger), groups of 25 late gastrulae (ciliated stage; $\sim 3 \mathrm{~d}$ old) were isolated from the mixed-stage embryos and placed into scintillation vials (two replicates per time point). These gastrulae were fed with two

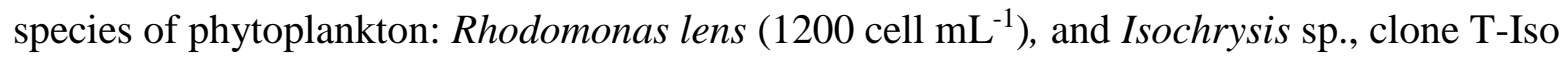
$\left(10,500\right.$ cell $\left.\mathrm{mL}^{-1}\right)$. Each day for four subsequent days, the developmental stages of the pteropods were classified. All of these observations were combined to create a full developmental timeline from fertilization through to the veliger stage.

\section{Calcein staining}

Initial calcification of larval shells is an important developmental milestone, and is known in other organisms to be a process sensitive to OA (Waldbusser et al. 2013; White et al. 2013; Waldbusser et al. 2015a; Waldbusser et al. 2015b). To monitor the initial calcification of $L$. retroversa, calcein staining was employed to identify calcium based structures during early development. A $50 \mathrm{mg} \mathrm{L}^{-1}$ solution of calcein dye was prepared in filtered seawater $(0.2 \mu \mathrm{m}$, collected in situ) and stored in the dark at $8{ }^{\circ} \mathrm{C}$. Gastrulae, trochophores, veligers and juveniles were placed into $3.5 \mathrm{~cm}$ diameter petri dishes containing the calcein solution. These manipulations were done on ice to minimize thermal stress. Developing pteropods were then incubated in the calcein solution for 1-24 h (durations were varied to determine optimal staining time) at $8{ }^{\circ} \mathrm{C}$ to fluorescently mark calcareous structures. After the calcein exposure, larvae and juveniles were rinsed three times with filtered seawater and incubated in clean scintillation vials with food as previously described.

\section{Light microscopy}


Developmental observations were made on living individuals under white transmitted light and UV epifluorescent light (Zeiss Fluoarc unit) using a Zeiss Axiovert 200 microscope and photographed using an AxioCam MRC camera and AxioVision 4.9.1.0 software. The diameter and surface area of egg capsules, gastrulae, trochophores, and veligers were measured using Image Pro Plus, Version 6 (Media Cybernetics, Inc.).

\section{Scanning Electron Microscope (SEM)}

For higher resolution observations of larval structures, embryos, trochophores and veligers were fixed for SEM following the protocol of Buckland-Nicks (2014) by first placing individuals in an isotonic primary fixative $(2.5 \%$ glutaraldehyde in $0.1 \mathrm{M}$ sodium cacodylate buffer, $0.06 \mathrm{M}$ sucrose, $\mathrm{pH}$ 7.4) on ice for $2 \mathrm{~h}$. The samples were then washed twice in $0.1 \mathrm{M}$ sodium cacodylate buffer for $10 \mathrm{~min}$, then post-fixed in isotonic secondary fixative $\left(1.25 \% \mathrm{OsO}_{4}\right.$ in 0.1 M sodium cacodylate, $0.21 \mathrm{M}$ sucrose, $\mathrm{pH}$ 7.4) for $1 \mathrm{~h}$. Finally, the samples were washed in distilled water ( 2 washes, $10 \mathrm{~min}$ each), dehydrated through a series of ethanol solutions (10\%, $30 \%, 50 \%, 70 \%, 80 \%, 90 \%, 95 \%$, and $100 \%, 10$ min each), and then dried using a critical point dryer (Tousimis Samdri-780A).

To observe shell morphology in veligers, we followed the protocol of Bednaršek et al. (2012b) with some modification. Larvae were fixed in 70\% ethanol for 4-6 d then transferred to $50 \%$ ethanol for $3 \mathrm{~min}$. Samples were washed in distilled water (two washes, $10 \mathrm{~min}$ each), 6\% $\mathrm{H}_{2} \mathrm{O}_{2}$ (to remove salt crystals, two washes, 15 min each), and again in distilled water (two washes, three $3 \mathrm{~min}$ each). Samples were dehydrated through a series of methanol solutions $(10 \%, 30 \%, 50 \%, 70 \%$, and $85 \%, 10 \mathrm{~min}$ each). Samples were transferred into 2,2Dimethoxypropane (DMP; 2 washes in DMP, 15 min each), a 1:1 mixture of DMP and 1,1,1,3,3,3-Hexamethyldisilazane (HMDS; $10 \mathrm{~min}$ ), and finally into 100\% HMDS, which acts as a critical point dryer ( 2 washes in HMDS, 20 min each). All specimens for SEM were mounted on SEM stub tape, sputter coated with $10 \mathrm{~nm}$ platinum (Leica MED 020), and visualized using a scanning electron microscope (Zeiss Supra40VP).

Confocal laser scanning microscopy 
Because the egg capsule prevented high resolution SEM images of earlier life stages, live calcein-stained and unstained pteropods (late gastrula to trochophore stages) were mounted in seawater on a 35-mm covered glass-bottomed dish and observed using a laser scanning confocal system (Zeiss LSM-710) with a 40x water-immersion objective (inverted Observer Z1 microscope). All imaging was conducted under plane and stack scan modes with a $488 \mathrm{~nm}$ excitation wavelength, and the emission was taken with a long pass 493-616 nm filter.

Larval $\mathrm{CO}_{2}$ exposure

Two $\mathrm{CO}_{2}$ exposure experiments were performed; experiment 1 began on the $21^{\text {st }}$ of August 2014, and experiment 2 on the $7^{\text {th }}$ of November 2014. Both were maintained at $8 \pm 1{ }^{\circ} \mathrm{C}$. Two days after eggs were laid, embryos in the gastrula stage from multiple adults were mixed and transferred to crystallization dishes containing $0.2-\mu \mathrm{m}$ filtered in situ seawater. Gastrulae were counted under a stereomicroscope and randomly distributed among glass culture tubes containing in situ $0.2-\mu \mathrm{m}$ filtered seawater that was pre-equilibrated with $\mathrm{CO}_{2}$ as follows: replicates of 40 gastrulae were added to $20 \mathrm{ml}$ for measurement on days 1, 2, or 3, while larger numbers and volumes were used for measurement on day 6 (replicates of 360 gastrulae in $50 \mathrm{ml}$ in Experiment 1, 240 gastrulae in $50 \mathrm{ml}$ in Experiment 2). This difference in number of individuals per replicate was chosen to allow for sufficient numbers of surviving individuals on day 6. Embryos were exposed to three different levels of $\mathrm{CO}_{2}$ (ambient, 800 and 1200 ppm) by continuously bubbling with air mixtures that were created using a compressed air gas flow controller system. These levels were chosen to simulate end-of-century predicted levels of 800 ppm (high but only slightly undersaturated with respect to aragonite: $\Omega_{\mathrm{Ar}} \sim 1.0$ ), and future ocean levels of $1200 \mathrm{ppm}$ (high and undersaturated with respect to aragonite: $\Omega_{\mathrm{Ar}} \sim 0.7$ ), based on estimates of the IPCC Ar5. Three replicates were performed for each combination of day and treatment, except that, due to limited embryo availability, experiment 1 had only two replicates for the $800 \mathrm{ppm}$ treatment on day 2 and for all three treatments on day 6. To minimize evaporation and maintain constant salinity during the experiment, the gas lines were first passed through humidifying chambers (sealed 1-L jars containing seawater) before entering the culture tubes, which were sealed with parafilm. Embryos and larvae were fed on days 1, 3 and 5 with Isochrysis sp., clone T-Iso at a density of 10,500 cells $\mathrm{ml}^{-1}$. On days 1, 2, 3 and 6, individuals were gently transferred from the culture tubes into 20-ml crystallization dishes for observation. 
The number of surviving individuals and their stage distribution were assessed under a stereomicroscope.

Salinity, $\mathrm{pH}$ and temperature were measured on days $1,2,3$ and 6 of $\mathrm{CO}_{2}$ exposures in experiment one and, due to instrumentation error, only on days 4 and 6 in experiment two. Salinity in the vials containing the embryos was measured using a seawater refractometer (Hanna Instruments, model 96822). Due to the small volume of water in the culture tubes, $\mathrm{pH}$ and temperature were measured simultaneously in three separate culture tubes for each $\mathrm{CO}_{2}$ treatment. The $\mathrm{pH}$ was determined using a USB 4000 spectrometer with an Ls-1 light source and a FIA-Z-SMA-PEEK 100-mm flow cell (Ocean Optics, Dunedin, Florida, USA). Bottle samples for dissolved inorganic carbon (DIC) and total alkalinity (TA) measurements were collected prior to the experiment and hence represent the starting conditions. DIC and TA were measured from these bottle samples either on a Versatile Instrument for the Determination of Total Inorganic Carbon and Titration Alkalinity (3C VINDTA system; Marianda, Kiel, Germany) or using a DIC auto-analyzer (AS-C3, Apollo SciTech, Bogart, USA) via acidification, followed by non-dispersive infrared $\mathrm{CO}_{2}$ detection (LiCOR 7000: Wang and Cai 2004) and an Apollo SciTech alkalinity auto-titrator (Bogart, Georgia), a Ross combination $\mathrm{pH}$ electrode, and a pH meter (ORION 3 Star) based on a modified Gran titration method (Wang et al. 2013). Carbonate system parameters were then calculated using the CO2SYS software (Pierrot et al. 2006), applying the constants refitted by Dickson and Millero (1987), and the $\mathrm{KHSO}_{4}$ dissociation constant from Dickson (1990).

\section{Statistical analysis}

To determine whether there were significant effects of $\mathrm{CO}_{2}$ exposure on mortality during each day, percent survival data were arcsine-square root transformed to meet the assumptions of normality. The assumption of homogeneity of variance was not met so a Welch's one-way ANOVA was conducted, followed by Dunnett's T3 post hoc tests. To test for developmental delays, we conducted Chi-Square tests for each day with a Bonferroni adjustment for post-hoc analysis. Dead individuals were excluded to remove the effect of survival from the analysis, and counts of veligers were combined with counts of trochophores since they were only present as a 
small fraction of the individuals in the ambient treatments on day 6 during experiment 2 , causing them to skew the statistical analysis. All statistics were run in SPSS.

\section{Results}

Pteropod Life Cycle and Developmental Observations

Adult Limacina retroversa from the Gulf of Maine consistently laid fertilized eggs within the first $2 \mathrm{~d}$ of capture following each of the five seasonal cruises. In comparison with the four other cruises, relatively few fertilized eggs were laid following the January cruise. Mature individuals kept as brood stock laid smaller numbers of eggs throughout their captivity. Egg masses were laid in gelatinous ribbons. The embryos within the egg capsules hatched, developed into veligers after 6-7 d, and developed into juveniles in 1-2 months. By 3 months, individuals began to produce eggs. Adults continued to increase in size and produce eggs for another 3 months, reaching the largest size reported in the literature (> $2.5 \mathrm{~mm}$; Hsiao 1939; Redfield 1939), after which individuals died ( 6 months; Table 1). Additional, qualitative observations of feeding and behavior during culturing are included in Electronic Supplementary Material.

Limacina retroversa embryos were usually spherical, about $\sim 80 \mu \mathrm{m}$ in diameter (Electronic Supplementary Material), and enveloped by a transparent egg capsule that was spherical at oviposition and became more oval during cleavage until hatching. Polar bodies were observed in all embryonic developmental stages until hatching and were attached to the surface of the embryos. After spawning, cleavage occurred following a typical molluscan developmental pattern (spiral holoblastic, Fig. 1). The first division was equal and parallel to the animal-vegetal axis, and polar bodies were observed at the animal pole (Fig. 1 B). The second cleavage was apparently equal and was perpendicular to the first cleavage and the cleavage furrows between the 4 blastomeres were visible (Fig. 1C).

The gastrula, identifiable by the characteristic blastopore, was observed at $24 \mathrm{~h}$ (Fig. 1F). Gastrulae started to spin inside the capsule $\sim 36 \mathrm{~h}$ after oviposition. After $\sim 48 \mathrm{~h}$ gastrulae began to develop cilia on their surface and a shell gland (observed as a black granule under light microscopy) at the depression of the ectoderm (Fig. $1 \mathrm{G}$ ). The egg capsule gradually became 
weak and was broken by spinning motions of the embryos, which hatched into free-swimming trochophores after $\sim 3 \mathrm{~d}$ (Fig.1 H).

Newly hatched trochophores were slightly oval, and smaller than developing embryos (Electronic Supplementary Material). Larvae swam horizontally and rotated using the prototroch on the apical end (Fig. 2A, B). During the early trochophore stage, the shell field was located on the lateral side of the body (Fig. 2B, C) and occupied $21 \pm 6 \%$ of the trochophore surface area. The shell field gradually decreased in size, migrated posteriorly along the lateral side (Fig. 1H), ending up on the posterior portion of the hyposphere (Fig. 2D). During trochophore development, the number and length of the cilia within the ciliary band increased. As the larvae transitioned from trochophore to veliger, a cup-shaped structure appeared to be secreted by the shell field (Fig. 2E, F).

Veligers were characterized by the development of the velum and the transparent protoconch shell, which has a characteristic cup-like shape (Fig. 1I). The velum, or feeding organ, increased in size to form ciliated lobes with longer and more numerous cilia. At this point, the larvae were able to swim in all directions and rotate by the velum (Fig. 1J, K). Veligers grew continuously, beginning to exhibit a sinistral coil (Fig. 1J, 3C) and development of a thinner, smoother operculum (Fig. 1J, 3A-B). Individuals began to develop parapodia ("wings", Fig. 1K) and produced shells with at least 2.5 whorls before metamorphosing into juveniles, losing their velum and using the parapodia for locomotion (Fig. 1L). By the time juveniles had accumulated an average of 3.2 whorls, the juvenile shell had increased $\sim$ five-fold in diameter (Electronic Supplementary Material).

\section{Early Calcification}

Calcein staining of embryological development was conducted to enable visualization of initial calcification by L. retroversa embryos. Late-stage gastrulae, trochophore and veligers showed no changes in behavior, malformations, or increased mortality following exposure to the calcein solution. Structure of the shell field and larval shell was well-marked with calcein and produced a distinct green label under fluorescent light. The level of fluorescence after $1 \mathrm{~h}$ exposure was sufficiently bright to not require the longer staining periods that were tested (up to $24 \mathrm{~h}$ ), 
providing a more discrete snapshot of calcification. If visualized immediately after staining, some internal organs (e.g., the gut) were marked with calcein (Figs. 4 and 5); however, in organisms stained for $1 \mathrm{~h}$, this internal staining faded within $1 \mathrm{~d}$, leaving fluorescence visible only in structures that were presumably calcium carbonate up to $21 \mathrm{~d}$ later.

Short exposure $(1 \mathrm{~h})$ of late-stage gastrulae to calcein faintly stained the shell gland (Fig. 4 A). Similarly, during the trochophore stage $1 \mathrm{~h}$ of calcein staining was sufficient to label initial shell formation within the shell field (Fig. 4 B). For greater resolution of this critical stage, stained trochophores were visualized using confocal laser scanning microscopy. Large stained granules were visible at the posterior end of the embryo and around the shell field, and smaller granules were also seen distributed along the body (Fig. 4C).

Calcein staining revealed that some form of calcium deposition is associated with the formation of the earliest cup-shaped structure by late-stage trochophores (Fig. 2E, F), as this stain remained visible in the protoconch $10 \mathrm{~d}$ after removal from calcein after the transition of the trochophore into the veliger stage (Fig. 4D). Veligers had a well-developed protoconch shell that surrounded the whole larval body and an operculum with a thinner and smoother surface (Fig. 3A-C). The protoconch of 2-week veligers was very thin (1.7-2.4 $\mu \mathrm{m})$ and smooth. At this point it was observable that the veliger shell was comprised of both an inner cross-lamellar layer and very thin outer prismatic layer (Fig. 3 D). As the veliger shells grew, a suture was apparent between the smooth older portion and the rough growth margin (Fig. 3E, F). Veligers showed staining at the growth margin and along the sutures of the shell (Fig. 5). Immediate visualization after $1 \mathrm{~h}$ of staining showed labeling of internal organs (Fig. 5A); however, within $1 \mathrm{~d}$, the calcein was lost from the internal organs leaving only stained shell and mantle structures. The staining of the mantle was particularly clear in early veligers. Time lapse images of a 1.5 weekold veliger showing an individual coming out of its shell display a circle of fluorescing granules (Fig. 4E). Due to the position and calcein labeling, this circle is likely to be mantle tissue, which secretes new shell as the organism grows. Although labeled $5 \mathrm{~d}$ previously, the shell has no calcein staining, while these internal granules persistently retained whatever calcium was labeled during the $1 \mathrm{~h}$ of staining. In later stage veligers (3-weeks) and juveniles, the stain remained exclusively in the shell throughout the $21 \mathrm{~d}$ of observation. Occasionally there were lines of 
fluorescence and possible repair at points more proximal to the protoconch along the shell (Fig. 5B). Calcein marked early juveniles of L. retroversa with varying degrees of brightness. Irrespective of staining intensity, over time the distinct green line established during calcein staining became clearer due to the growth at the margin of the unlabeled shell (Fig. 5C).

$\mathrm{CO}_{2}$ exposure experiments

Bubbling of experimental seawater achieved distinct carbonate chemistry among treatments during both experiments (Table 2). Although it appears that there was a lower ambient $\mathrm{pCO}_{2}$ in August (experiment 1) which influenced the gas mixtures, the aragonite saturation states for ambient were consistently $>1$, the medium treatment was close to 1 and high was strongly understaturated $\left(\Omega_{\mathrm{Ar}}=0.73\right.$ in August and 0.63 in November).

$\mathrm{CO}_{2}$ exposure resulted in decreased survival of pteropod embryos and larvae in both experiments (Table 3; Fig. 6). Although the data were normally distributed post-transformation, the homogeneity of variance assumption of the ANOVA was not met in either experiment. The low number of replicates ( 2 or 3 per time point) likely contributed to this deviation. In the first experiment, survival on day one was substantially reduced in the high $\mathrm{CO}_{2}(1200 \mathrm{ppm})$ treatment (Table 3). Survival decreased over time, and by day six there was heavy mortality in all treatments. There were significant differences among the 3 treatments on days 1 and 6 (Welch's one-way ANOVA; Table 3). During the second experiment, a similar trend of decreasing survival was apparent in all treatments, although overall mortality was less severe by day 6 (Table 3). There were significant effects of treatment during days 2 and 6, with generally higher mortality in the elevated $\mathrm{CO}_{2}$ treatments (Table 3). Post-hoc analysis of survival generally suggested significant differences $(P<0.05)$ in survival rate in the high $(1200 \mathrm{ppm})$ treatment in comparison with the ambient and 800 ppm treatments (Fig. 6).

We detected significant differences (Asymptotic significance $<0.05$ ) in relative proportions of stages on days 3 and 6 during experiment 1 and on days 1 and 6 in experiment 2 (Electronic Supplementary Material). These were indicative of a trend towards a developmental delay, with a larger proportion of earlier life stages in the high treatment (1200 ppm) relative to ambient towards the end of experiment 1, and throughout the exposure in experiment 2 . In 
contrast, the $800 \mathrm{ppm}$ treatment appeared to have a similar proportion of life stages to the ambient treatment during both experiments (Fig. 7; Electronic Supplementary Material).

\section{Discussion}

The present study provides new information on the life cycle, development, and early calcification of the thecosome pteropod Limacina retroversa. This species can produce egg masses after only 3 mo of development in the laboratory at $8^{\circ} \mathrm{C}$, and it is thus likely that two generations $\mathrm{y}^{-1}$ are produced by the Gulf of Maine population. Initial calcification occurs as early as the gastrula stage when the embryo is still encapsulated, and early life stages appear to be sensitive to elevated $\mathrm{CO}_{2}$ levels.

Seasonal sampling of thecosomes from the Gulf of Maine consistently resulted in the capture of reproductively active adults that produced fertilized eggs. This is similar to observations of L. retroversa off Plymouth, U.K. (Lebour 1932). While some of the spawning observed was likely a response to the stress of capture, these observations indicated that some proportion of the population may be fertile year-round. Higher temporal resolution sampling would be required, however, to contradict the findings of Hsiao (1939), which suggested that mature female L. retroversa were absent in December and January. Furthermore, after individuals reached reproductive maturity we observed continuous egg production, with eggs present at each weekly water change. Although they appear capable of producing viable eggs throughout all seasons, this does not necessarily imply that they are constantly reproducing in the wild. The Gulf of Maine is a dynamic ecosystem with large annual changes in surface temperature. We collected adult pteropods in the upper $100 \mathrm{~m}$ of the water column, where concurrent hydrographic sampling indicated they would experience temperatures ranging from 6-18 ${ }^{\circ} \mathrm{C}$. Nearby PMEL/NOAA buoy data of surface seawater carbonate chemistry indicate that there is also a yearly cycle of higher than global average $\mathrm{CO}_{2}$ in the winter (up to $500 \mathrm{ppm}$ ), followed by a drawdown in the spring by the phytoplankton bloom to ca. $200 \mathrm{ppm}$, equivalent to lower than pre-industrial levels (Vandemark et al. 2011). Thus, the growth and spawning of these individuals occurs within the context of a much more variable environment than that experienced in our laboratory culture (constant food, light, $\sim 400 \mathrm{ppm} \mathrm{CO}_{2}, 8^{\circ} \mathrm{C}$ ), and it is likely that the 
natural population reacts to feeding history and synchronizes reproduction with favorable environmental conditions.

Previously, based on seasonal size-class sampling and analyses of gonad development, indications were that L. retrovers $a$ in the Gulf of Maine exhibits peak spawning activity in May (Hsiao 1939), but that reproduction also continues actively into the fall. The authors also noted that reproductive development appeared to occur more rapidly in the summer, although it was also hypothesized that the two size cohorts observed in the region were a consequence of two unrelated populations of $L$. retrovers $a$ which were advected into the Gulf of Maine from offshore (Hsiao 1939; Redfield 1939). Studies of the South Atlantic population of L. retroversa similarly indicated that the major pulses of reproduction occurred in spring and at the end of summer (Dadon and Cidre 1992). In this case, however, the authors suggested that there were two generations per year, with individuals born in the spring maturing at a smaller size and growing faster during the warm season to produce eggs at the end of summer which then slowly developed during the fall and winter to produce offspring the following spring. Based on their apparent life span ( $\sim 6$ months), it seems likely that there is more than one generation per year in the Gulf of Maine region and that this population shares a similar life history pattern to that reported for L. retroversa from the South Atlantic. This is also the pattern described for the congener L. helicina (Kobayashi 1974; Wang 2014). The production of two distinct cohorts has interesting consequences in the context of juvenile exposure to environmental stress, as individuals released during the spring bloom and developing during the summer would naturally experience very different conditions from those released at the end of the summer and developing through the fall and winter.

While we expect that developmental rates in the environment vary seasonally, we were able to repeatedly rear $L$. retroversa through embryonic and juvenile stages under controlled laboratory conditions at $8{ }^{\circ} \mathrm{C}$, and generate a timeline for normal development. High resolution imagery also allowed examination of the typical morphology of trochophore and veliger development and shell deposition. Similar to the earliest reports of L. retroversa development (Lebour 1932), our embryos hatched from the egg capsule as a trochophore. This is different from descriptions of other species in the genus such as L. helicina (Paranjape 1968) and $L$. 
trochiformis (Bandel and Hemleben 1995) that were reported to hatch as veligers (with a shell and velum). Another interesting outcome of developmental observations was our documentation of the long duration of the developmental stages. Hatching from the egg capsule as trochophore took about $3 \mathrm{~d}$, with a transition to the veliger stage after about a week. In contrast, the other study documenting $L$. retroversa development by Lebour (1932), reported hatching after only 1 $\mathrm{d}$, with a transition to veliger sometime around $4 \mathrm{~d}$ (temperature not reported). Embryos of $L$. helicina (Paranjape 1968) hatched as veligers after $2 \mathrm{~d}$ at $13{ }^{\circ} \mathrm{C}$, but did not metamorphose to juveniles after $30 \mathrm{~d}$ of observation when the experiment was ended. This long veliger stage, which in our experiment lasted 1-2 months and was also reported as lasting $\sim 40-50 \mathrm{~d}$ for $L$. retroversa at $10^{\circ} \mathrm{C}$ in Howes et al. (2014), may explain the lack of observed metamorphosis in Paranjape (1968). As thecosome pteropods spend the entirety of their lives in the plankton, perhaps there is little or no evolutionary pressure to rapidly transition to the juvenile stage.

Studies conducted on diverse mollusc species have clearly shown that early life stages (Kroeker et al. 2013) and initial biomineralization windows (Waldbusser et al. 2013; White et al. 2013; Waldbusser et al. 2015a; Waldbusser et al. 2015b) are particularly sensitive to ocean acidification. Thus, the point at which biomineralization begins in L. retroversa is an important developmental benchmark, and tracking the normal progression of early shell formation provides a point of reference to enable assessments of the effects of OA. In this study, we documented early calcification in L. retroversa through calcein staining paired with fluorescent, SEM, and confocal microscopy. Recently, calcein staining has been used to study the effects of OA on scallop larvae (Andersen et al. 2013), as well as pteropod adults (Comeau et al. 2009) and juveniles (Lischka et al. 2011). Calcification by veligers of the pteropod Cavolinia inflexa was also observed under ambient and acidified conditions (Comeau et al. 2010b), revealing the reduction or loss of shells during development when larvae were reared in acidified water.

In our study, calcein staining marked the shell gland and presumed initial site of shell deposition, beginning with the appearance of stained granules in late gastrulae and the development of a cup-shaped shell in trochophores. Using these methods, however, it is not possible to determine whether the stained granules indicate the presence of calcium carbonate, or some other form of stored calcium (e.g., in a vacuole). In addition, the form of calcium carbonate 
present during the earliest stages of shell formation is unknown. Amorphous calcium carbonate (ACC) has been shown to be the initial building material for shells of many other molluscs (Weiss et al. 2002; Marin et al. 2012) and based on preliminary microscopy data, it appears that this may be the case for thecosomes as well (Gallager pers. comm.). Based on results from other species and due to its granular appearance, we consider it likely that in L. retoversa the initial cup-shaped shell is comprised mainly of an organic matrix and ACC. Because ACC is more soluble than aragonite, if initial L. retroversa biomineralization structures are comprised of ACC, then OA may pose an increased risk during larval stages.

Mineralogical studies on other molluscs have revealed a gradual replacement of the organic protoconch by ACC (Auzoux-Bordenave et al. 2010). Although our methods did not provide the same degree of mineralogical resolution, the protoconch II laid down in the veliger stage is clearly distinct in surface morphology from the protoconch I, suggesting a transition to aragonite deposition as has been seen in other molluscan species (Weiss et al. 2002; AuzouxBordenave et al. 2010). Little was known about the structure of veliger shells in thecosome pteropods, but we identified the thick inner cross-lamellar layer and very thin outer prismatic layer in $L$. retroversa by two weeks into the veliger stage. This is consistent with what is known from adults of the congeners L. bulimoides, L. lesueuri, L. helicina and L. helicina antarctica, the shells of which are similarly composed of an inner cross-lamellar layer of aragonite crystals and an outer prismatic layer (Bé and Gilmer 1977; Sato-Okoshi et al. 2010; Bednaršek et al. 2012a). Sato-Okoshi et al. (2010) did, however, observe a third inner prismatic layer in large specimens of $L$. helicina antarctica. Whether this third layer is similarly present in large adults of $L$. retroversa remains to be established. This is the first confirmation that $L$. retroversa shell structure is consistent with that of its congeners, and supports previous findings that the aragonitic layer structure of adult thecosome shells appears to be largely conserved within families (Bé et al. 1972; Bé and Gilmer 1977; Sato-Okoshi et al. 2010; Zhang et al. 2011; Teniswood et al. 2013; Li et al. 2015).

Interestingly, fluorescent granules, similar to those observed in the late gastrula and early trochophores, were also present in the mantle tissue of veligers for multiple days after removal from calcein. This suggests that calcium, in some form, is also stored in the mantle. Similar 
granules have been described in other species of molluscs (Marin et al. 2012) and have been suggested to provide a source of calcium for shell repair (Fleury et al. 2008). Also during the veliger stage, minimal staining in the shell suggests that the shell deposition may not occur continuously. This hypothesis is supported by SEM images of two week-old veliger shells, which occasionally showed distinct regions of shell structural growth. Calcein staining was also observed at points other than the leading shell edge, including strong staining along the columella and in regions that may have been damaged during handling. Shell repair has previously been suggested to occur in Cavolinia uncinata and Diacria trispinosa by van der Spoel (1967), and our observations corroborate previous evidence that it also occurs in the limacinids (Lischka et al. 2011). While Comeau et al. (2009) observed staining only along the thecosome growth margin, our results are more similar to those of Lischka et al. (2011), who note that calcein stained not only the growth margin but also other regions around the protoconch.

Another objective of the present study was to gain initial insight into the effects of elevated $\mathrm{CO}_{2}$ on the survival and developmental progression of L. retroversa. We found that early exposure of $L$. retroversa to elevated $\mathrm{CO}_{2}(1200 \mathrm{ppm})$ caused increased mortality relative to the ambient and $800 \mathrm{ppm}$ treatments in two experiments. Increased mortality in response to OA exposure has been similarly observed in several previous studies with other larval molluscs, such as the bay scallop (1987 ppm; White et al. 2013), and the great scallop (1599 ppm; Andersen et al. 2013). In the only other study of the effects of OA on developing pteropods, Comeau et al. (2010b) found that mortality of Cavolinia inflexa was not influenced by OA exposure. While the results from Comeau's study were intriguing, the ambient and elevated $\mathrm{CO}_{2}$ treatments were applied to individuals from a single egg mass so that between-clutch differences could not be assessed. Furthermore, the study of $C$. inflexa started at the veliger stage, and it may be that the window of greater sensitivity is earlier in development when calcification begins.

Reports of the effect of OA on pteropod mortality have varied, with one study reporting increased mortality in juveniles of L. helicina (Lischka et al. 2011), and others finding no significant effects on juvenile or adult survival of C. inflexa, L. helicina or L. retroversa (Comeau et al. 2012; Lischka and Riebesell 2012; Manno et al. 2012). Our dataset suggests that 
survival during the early development of $L$. retroversa is sensitive to elevated levels of $\mathrm{CO}_{2}$. This is similar to trends observed in meta-analyses of molluscan sensitivity to OA, which indicate that early life stages are significantly more vulnerable than adults (Kroeker et al. 2013).

Beyond influencing survival, OA has been shown to affect the duration of development in many molluscan species (Timmins-Schiffman et al. 2013; Onitsuka et al. 2014; Guo et al. 2015). Our results indicate a developmental delay when comparing the high treatment relative to the ambient treatment. In contrast, the medium treatment $(800 \mathrm{ppm})$ was similar in stage distribution to the ambient throughout. Most of the previous work exploring the effects of OA on mollusc development rate have used species with a shorter larval duration (e.g., veligers appearing within 2 d) relative to $L$. retroversa (veligers within $\sim 1$ week). The selective pressures on these other species, for which the life history includes a transition to the benthic lifestyle and to calcite shell deposition, may be quite different than the selective pressures experienced by holoplanktonic thecosomes. Further experiments exploring these trends are warranted, as thecosome development offers a unique contrast to other molluscan developmental studies.

Although patterns were similar between our two experiments, both survival rate and developmental progression varied. The ambient $\mathrm{CO}_{2}$ in August was significantly lower than in November, which resulted in less acidified conditions in both the medium and high treatments. In addition, because the trials were conducted during different seasons, the larvae may have experienced differences in maternal provisioning that in turn could affect energy available for calcification and survival (Waldbusser et al. 2013). Alternately, the age distribution of individuals at the start of the incubation may have differed between experiments. While gastrulae were selected for both experiments, this stage lasts $1.5-2 \mathrm{~d}$, so individuals may have been older in the second trial. We also note that embryos from the normal developmental study (conducted in May) had a faster rate of development than those raised in our $\mathrm{CO}_{2}$ experiments (conducted in August and November). During the study of normal developmental progression, individuals transitioned from gastrulae to veligers within $5 \mathrm{~d}$, while within both $\mathrm{CO}_{2}$ experiments only a very small portion of the gastrulae reached the veliger stage by the end of the $6 \mathrm{~d}$ observation period. We do not know the cause of this difference, but variations in culture conditions (container size, continuous bubbling in the $\mathrm{CO}_{2}$ exposure) are the most likely source. 


\section{Future Directions}

In this study we captured wild specimens of thecosome L. retroversa and reared them through an entire captive generation, producing adults that began to lay eggs after approximately three months. To our knowledge $L$. retroversa is the only pteropod species that has been reared through a complete captive generation, and this is the first full description of time to maturity for a pteropod. Despite this progress, mortality was high in our cultures, similar to previous observations (Howes et al. 2014). Additional work is clearly needed to optimize culture conditions. Establishment of stable cultures would enable long-term and/or multigenerational experiments.

We found that $L$. retroversa calcification may begin as early as the gastrula stage and that a cup-shaped structure was formed during the early trochophore stage. Application of additional methods, such as birefringence, Raman spectroscopy and energy-dispersive X-ray spectroscopy will be needed to determine the mineral composition of structures in these early stages (as in Auzoux-Bordenave et al. 2010). In particular, we hypothesize that the initial cup-shaped structure is likely comprised primarily of organic matrix and ACC, and we are uncertain whether the granules observed during the gastrula stage are mineralized. These are important points to clarify, as ACC is more soluble than aragonite and could partially explain why the early life stages appear more sensitive to changing carbonate chemistry. Similarly, tests of calcification kinetics, maternal provisioning, and the window of calcification sensitivity remain to be conducted (sensu Waldbusser et al. 2013; 2015b). We hypothesize that embryos from different seasons have variable maternal provisioning, and that saturation state is the limiting factor during development, resulting in the observed differences in sensitivity to $\mathrm{CO}_{2}$ exposure during different experiments.

\section{Acknowledgements}

We would like to thank R. Galat, D. McCorkle, M. White, and C. Zakroff for assisting in the setup of the culturing and $\mathrm{CO}_{2}$ exposure facilities. We greatly appreciate the insight of D. McCorkle and the collaboration of Z.A. Wang and K. Hoering on the carbonate chemistry measurements. We much appreciate the hard work and dedication of Captain K. Houtler and Mate I. Hanley and would like to thank them for excellent support aboard the R/V Tioga. At sea 
sampling was supported by P. Alatalo, A. Bergan, L. Blanco Bercial, S. Chu, N. Copley, T. Crockford, S. Crosby, M. Edenius, K. Hoering, R. Levine, M. Lowe, C. Pagniello, A. Schlunk, Z.A. Wang, T. White, and P. Wiebe. A special thanks is owed to P. Alatalo, for critical assistance in maintaining long term cultures of pteropods and phytoplankton, providing insight and advice, and for consistent hard work during experiments. L. Kerr provided expertise with SEM and confocal microscopy at the Marine Biological Laboratory Central Microscopy Facility. We are grateful for advice from S. Gallager whose experience with pteropod rearing and visualization were profoundly helpful. A. Thabet is grateful for a fellowship from the Egyptian Culture and Education Bureau and for mentoring from Drs. S.A. Saber, M.M. Sarhan and M.M. Fouda. Funding for this research was provided by a National Science Foundation grant to Lawson, Maas, and Tarrant (OCE-1316040). Additional support for field sampling was provided by the WHOI Coastal Ocean Institute and Pickman Foundation to Wang, Maas, and Lawson. This paper is contribution number 3001 of the Bermuda Institute of Ocean Sciences. 


\section{References}

Albright R (2011) Reviewing the effects of ocean acidification on sexual reproduction and early life history stages of reef-building corals. J Mar Biol 2011: 14 doi 10.1155/2011/473615

Andersen S, Grefsrud ES, Harboe T (2013) Effect of increased $\mathrm{pCO}_{2}$ level on early shell development in great scallop (Pecten maximus Lamarck) larvae. Biogeosciences 10: 6161-6184 doi 10.5194/bg-10-6161-2013

Auzoux-Bordenave S, Badou A, Gaume B, Berland S, Helléouet M-N, Milet C, Huchette S (2010) Ultrastructure, chemistry and mineralogy of the growing shell of the European abalone Haliotis tuberculata. J Struct Biol 171: 277-290

Bandel K, Hemleben C (1995) Observations on the ontogeny of thecosomatous pteropods (holoplanktic Gastropoda) in the southern Red Sea and from Bermuda. Mar Biol 124: 225-243

Bé AWH, Gilmer RW (1977) A zoogeographic and taxonomic review of Euthecosomatous Pteropoda. In: Ramsay A (ed) Oceanic micropalaeontology. Academic Press, London, pp 733-808

Bé AWH, MacClintock C, Currie DC (1972) Helical shell structure and growth of the pteropod Cuvierina columnella (Rang)(Mollusca, Gastropoda). Biomineralization 4: 47-79

Bednaršek N, Feely R, Reum J, Peterson B, Menkel J, Alin S, Hales B (2014) Limacina helicina shell dissolution as an indicator of declining habitat suitability owing to ocean acidification in the California Current Ecosystem. P Roy Soc B-Biol Sci 281: 20140123

Bednaršek N, Tarling G, Bakker D, Fielding S, Jones E, Venables H, Ward P, Kuzirian A, Lézé B, Feely R (2012a) Extensive dissolution of live pteropods in the Southern Ocean. Nat Geosci 5: 881-885

Bednaršek N, Tarling GA, Bakker DCE, Fielding S, Cohen A, Kuzirian A, McCorkle D, Lézé B, Montagna R (2012b) Description and quantification of pteropod shell dissolution: a sensitive bioindicator of ocean acidification. Glob Change Biol 18: 2378-2388 doi 10.1111/j.1365-2486.2012.02668.x

Bigelow HB (1924) Plankton of the offshore waters of the Gulf of Maine. Govt. print. off.

Buckland-Nicks J (2014) SEM analysis of marine invertebrate gametes. In: Carroll DJ, Stricker SA (eds) Developmental biology of the sea urchin and other marine invertebrates. Humana Press, pp 125-145

Comeau S, Alliouane S, Gattuso J-P (2012) Effects of ocean acidification on overwintering juvenile Arctic pteropods Limacina helicina. Mar Ecol-Prog Ser 456: 279-284

Comeau S, Gorsky G, Alliouane S, Gattuso JP (2010b) Larvae of the pteropod Cavolinia inflexa exposed to aragonite undersaturation are viable but shell-less. Mar Biol 157: 2341-2345 doi DOI: 10.1007/s00227-010-1493-6

Comeau S, Gorsky G, Jeffree R, Teyssie J, Gattuso JP (2009) Impact of ocean acidification on a key Arctic pelagic mollusc (Limacina helicina). Biogeosciences 6: 1877-1882

Comeau S, Jeffree R, Teyssié JL, Gattuso JP (2010a) Response of the Arctic pteropod Limacina helicina to projected future environmental conditions. PLoS One 5: e11362

Cripps G, Lindeque P, Flynn KJ (2014) Have we been underestimating the effects of ocean acidification in zooplankton? Glob Change Biol 20: 3377-3385 doi 10.1111/gcb.12582

Dadon JR, Cidre LL (1992) The reproductive cycle of the thecosomatous pteropod Limacina retroversa in the western South Atlantic. Mar Biol 114: 439-442

Dickson AG (1990) Thermodynamics of the dissociation of boric acid in synthetic seawater from 273.15 to 318.15 K. Deep-Sea Res 37: 755-766 
Dickson AG, Millero FJ (1987) A comparison of the equilibrium constants for the dissociation of carbonic acid in seawater media. Deep-Sea Res 34: 1733-1743

Dupont S, Havenhand J, Thorndyke W, Peck L, Thorndyke M (2008) Near-future level of $\mathrm{CO}_{2}$ driven ocean acidification radically affects larval survival and development in the brittlestar Ophiothrix fragilis. Mar Ecol-Prog Ser 373: 285-294

Fabry VJ, Seibel BA, Feely RA, Orr JC (2008) Impacts of ocean acidification on marine fauna and ecosystem processes. ICES J Mar Sci 65: 414-432 doi 10.1093/icesjms/fsn048

Fleury C, Marin F, Marie B, Luquet G, Thomas J, Josse C, Serpentini A, Lebel J-M (2008) Shell repair process in the green ormer Haliotis tuberculata: A histological and microstructural study. Tissue Cell 40: 207-218

Gannefors C, Böer M, Kattner G, Graeve M, Eiane K, Gulliksen B, Hop H, Falk-Petersen S (2005) The Arctic sea butterfly Limacina helicina: lipids and life strategy. Mar Biol 147: 169-177

Guo X, Huang M, Pu F, You W, Ke C (2015) Effects of ocean acidification caused by rising $\mathrm{CO}_{2}$ on the early development of three mollusks. Aquat Biol 23: 147-157 doi 10.3354/ab00615

Hendriks IE, Duarte CM, Álvarez M (2010) Vulnerability of marine biodiversity to ocean acidification: A meta-analysis. Estuar Coast Shelf S 86: 157-164

Howes EL, Bednaršek N, Büdenbender J, Comeau S, Doubleday A, Gallager SM, Hopcroft RR, Lischka S, Maas AE, Bijma J (2014) Sink and swim: a status review of thecosome pteropod culture techniques. J Plankton Res 36: 299-315

Hsiao SCT (1939) The reproduction of Limacina retroversa (Flem.). Biol Bull 76: 280-303 doi $10.2307 / 1537865$

Hunt BPV, Pakhomov EA, Hosie GW, Siegel V, Ward P, Bernard K (2008) Pteropods in Southern Ocean ecosystems. Prog Oceanogr 78: 193-221

Kaehler S, McQuaid C (1999) Lethal and sub-lethal effects of phototrophic endoliths attacking the shell of the intertidal mussel Perna perna. Mar Biol 135: 497-503

Kobayashi HA (1974) Growth cycle and related vertical distribution of the thecosomatous pteropod Spiratella ("Limacina") helicina in the central Arctic Ocean. Mar Biol 26: 295301 doi 10.1007/BF00391513

Kroeker KJ, Kordas RL, Crim R, Hendriks IE, Ramajo L, Singh GS, Duarte CM, Gattuso JP (2013) Impacts of ocean acidification on marine organisms: quantifying sensitivities and interaction with warming. Glob Change Biol 19: 1884-1896

Kroeker KJ, Kordas RL, Crim RN, Singh GG (2010) Meta-analysis reveals negative yet variable effects of ocean acidification on marine organisms. Ecol Lett 13: 1419-1434

Kurihara $\mathrm{H}$ (2008) Effects of $\mathrm{CO}_{2}$-driven ocean acidification on the early developmental stages of invertebrates. Mar Ecol-Prog Ser 373: 275-284

Lalli CM, Gilmer RW (1989) Pelagic snails: The biology of holoplanktonic gastropod mollusks. Stanford University Press, Stanford, CA

Lalli CM, Wells FE (1978) Reproduction in the genus Limacina (Opisthobranchia: Thecosomata). J Zool 186: 95-108

Lebour MV (1932) Limacina retroversa in Plymouth waters. J Mar Biol Assoc UK 18: 123-126

Li L, Weaver JC, Ortiz C (2015) Hierarchical structural design for fracture resistance in the shell of the pteropod Clio pyramidata. Nat Commun 6: 6216 doi doi:10.1038/ncomms 7216

Lischka S, Riebesell U (2012) Synergistic effects of ocean acidification and warming on overwintering pteropods in the Arctic. Glob Change Bio 18: 3517-3528 
Lischka S, Büdenbender J, Boxhammer T, Riebesell U (2011) Impact of ocean acidification and elevated temperatures on early juveniles of the polar shelled pteropod Limacina helicina: mortality, shell degradation, and shell growth. Biogeosciences 8: 919-932 doi 10.5194/bg-8-919-2011

Manno C, Morata N, Primicerio R (2012) Limacina retroversa's response to combined effects of ocean acidification and sea water freshening. Estuar Coast Shelf S 113: 163-171

Marin F, Le Roy N, Marie B (2012) The formation and mineralization of mollusk shell. Front Biosci S 4: 1099-1125

Millero FJ (2007) The marine inorganic carbon cycle. Chem Rev 107: 308-341

Moran AL (2000) Calcein as a marker in experimental studies newly-hatched gastropods. Mar Biol 137: 893-898 doi 10.1007/s002270000390

Moran AL, Marko PB (2005) A simple technique for physical marking of larvae of marine bivalves. J Shellfish Res 24: 567-571

Onitsuka T, Kimura R, Ono T, Takami H, Nojiri Y (2014) Effects of ocean acidification on the early developmental stages of the horned turban, Turbo cornutus. Mar Biol 161: 11271138 doi 10.1007/s00227-014-2405-y

Paranjape MA (1968) The egg mass and veligers of Limacina helicina Phipps. Veliger 10: 322326

Pierrot D, Lewis E, Wallace D (2006) Co2sys DOS Program developed for $\mathrm{CO}_{2}$ system calculations. Carbon Dioxide Information Analysis Center, Oak Ridge National Laboratory, US Department of Energy ORNL/CDIAC-105

Pörtner HO (2008) Ecosystem effects of ocean acidification in times of ocean warming: a physiologist's view. Mar Ecol-Prog Ser 373: 203-217

Redfield AC (1939) The history of a population of Limacina retroversa during its drift across the Gulf of Maine. Biol Bull 76: 26-47

Sato-Okoshi W, Okoshi K, Sasaki H, Akiha F (2010) Shell structure of two polar pelagic molluscs, Arctic Limacina helicina and Antarctic Limacina helicina antarctica forma antarctica. Polar Biol 33: 1577-1583

Teniswood CM, Roberts D, Howard WR, Bradby JE (2013) A quantitative assessment of the mechanical strength of the polar pteropod Limacina helicina antarctica shell. ICES J Mar Sci 70: 1499-1505 doi 10.1093/icesjms/fst100

Timmins-Schiffman E, O'Donnell MJ, Friedman CS, Roberts SB (2013) Elevated $\mathrm{pCO}_{2}$ causes developmental delay in early larval Pacific oysters, Crassostrea gigas. Mar Biol 160: 1973-1982

van der Geest M, van Gils JA, van der Meer J, Olff H, Piersma T (2011) Suitability of calcein as an in situ growth marker in burrowing bivalves. J Exp Mar Biol Ecol 399: 1-7

van der Spoel S (1967) Euthecosomata: A group with remarkable developmental stages (Gastropoda, Pteropoda). Noorduijn en Zoon, Gorinchem

Vandemark D, Salisbury JE, Hunt CW, Shellito SM, Irish JD, McGillis WR, Sabine CL, Maenner SM (2011) Temporal and spatial dynamics of $\mathrm{CO}_{2}$ air-sea flux in the Gulf of Maine. J Geophys Res-Oceans 116 doi 10.1029/2010jc006408

Waldbusser GG, Brunner EL, Haley BA, Hales B, Langdon CJ, Prahl FG (2013) A developmental and energetic basis linking larval oyster shell formation to acidification sensitivity. Geophys Res Lett 40: 2171-2176 
Waldbusser GG, Hales B, Langdon CJ, Haley BA, Schrader P, Brunner EL, Gray MW, Miller CA, Gimenez I (2015a) Saturation-state sensitivity of marine bivalve larvae to ocean acidification. Nat Clim Change 5: 273-280

Waldbusser GG, Hales B, Langdon CJ, Haley BA, Schrader P, Brunner EL, Gray MW, Miller CA, Gimenez I, Hutchinson G (2015b) Ocean acidification has multiple modes of action on bivalve larvae. PloS One 10: e0128376

Wang K (2014) The life cycle of the pteropod Limacina helicina in Rivers Inlet (British Columbia, Canada). Dissertation, The University of British Columbia, Vancouver

Wang ZA, Cai W-J (2004) Carbon dioxide degassing and inorganic carbon export from a marshdominated estuary (the Duplin River): A marsh $\mathrm{CO}_{2}$ pump. Limnol Oceanogr 49: 341354

Weiss IM, Tuross N, Addadi L, Weiner S (2002) Mollusc larval shell formation: amorphous calcium carbonate is a precursor phase for aragonite. J Exp Zool 293: 478-491

White MM, McCorkle DC, Mullineaux LS, Cohen AL (2013) Early exposure of bay scallops (Argopecten irradians) to high $\mathrm{CO}_{2}$ causes a decrease in larval shell growth. PLoS One 8: e61065 doi 10.1371/journal.pone.0061065

Zhang T, Ma Y, Chen K, Kunz M, Tamura N, Qiang M, Xu J, Qi L (2011) Structure and mechanical properties of a pteropod shell consisting of interlocked helical aragonite nanofibers. Angew Chem Int Ed 123: 10545-10549 doi 10.1002/anie.201103407

\section{Conflict of interest}

The authors declare that they have no conflicts of interest. 

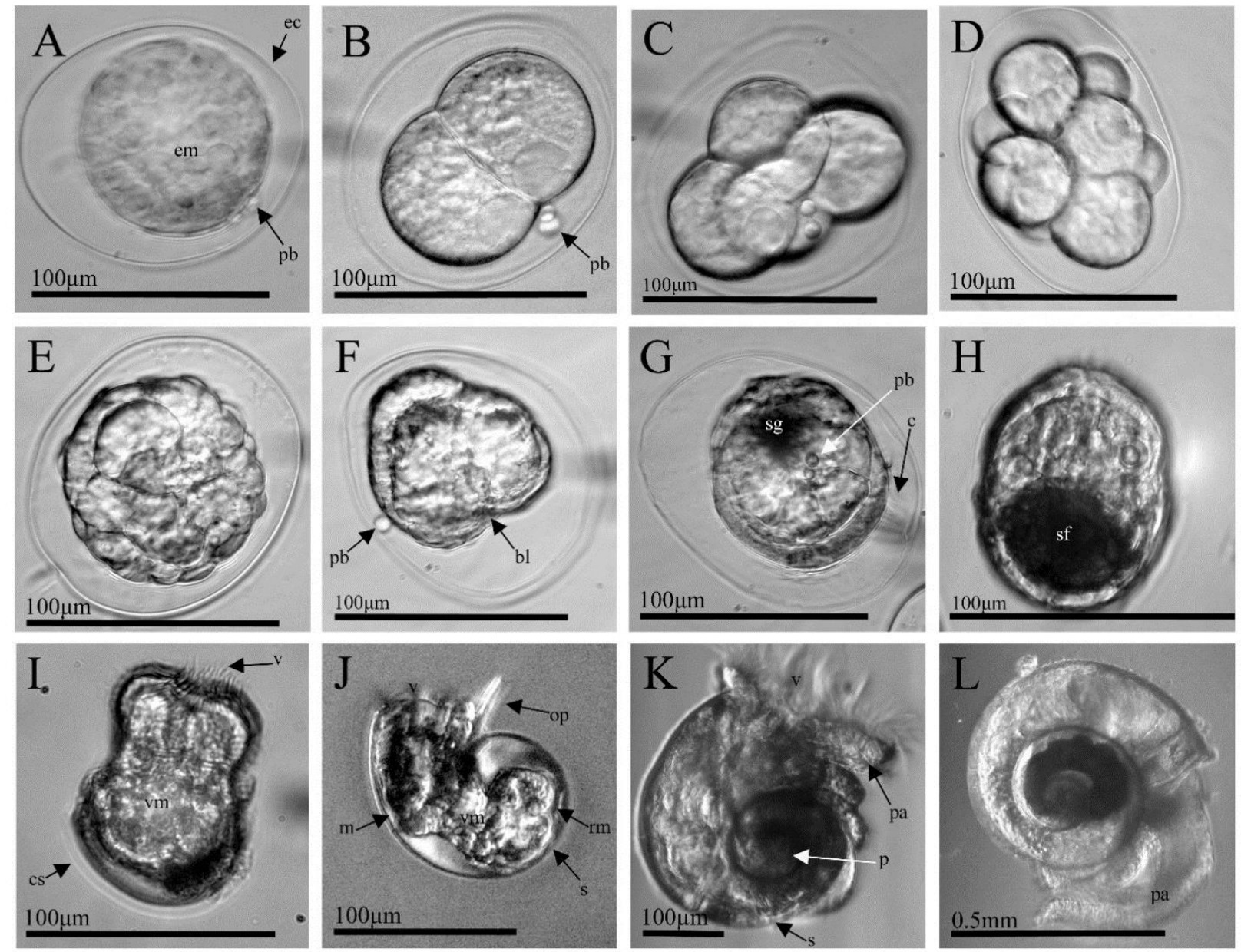

Fig. 1 Embryonic and larval development of L. retroversa observed via light microscopy. A, Fertilized egg with two polar bodies; B, 2-cell stage with polar bodies; C, 4-cell stage; D, 8-cell stage; E, blastula; F, early gastrula with blastopore and polar body; G, late gastrula, showing formation of shell gland and cilia on the surface; $\mathrm{H}$, trochophore, showing shell field; I, early veliger with cup-like structure; J, 1-week old veliger; K, 3-week old veliger; and L, juvenile. Abbreviations: bl, blastopore; c, cilia; cs, cup-shaped structure; ec, egg capsule; em, embryo; m, mantle; op, operculum; p, protoconch; pa, parapodia; pb, polar body; rm, retractor muscles; s, shell; sf, shell field; sg, shell gland; v, velum; vm; visceral mass. 

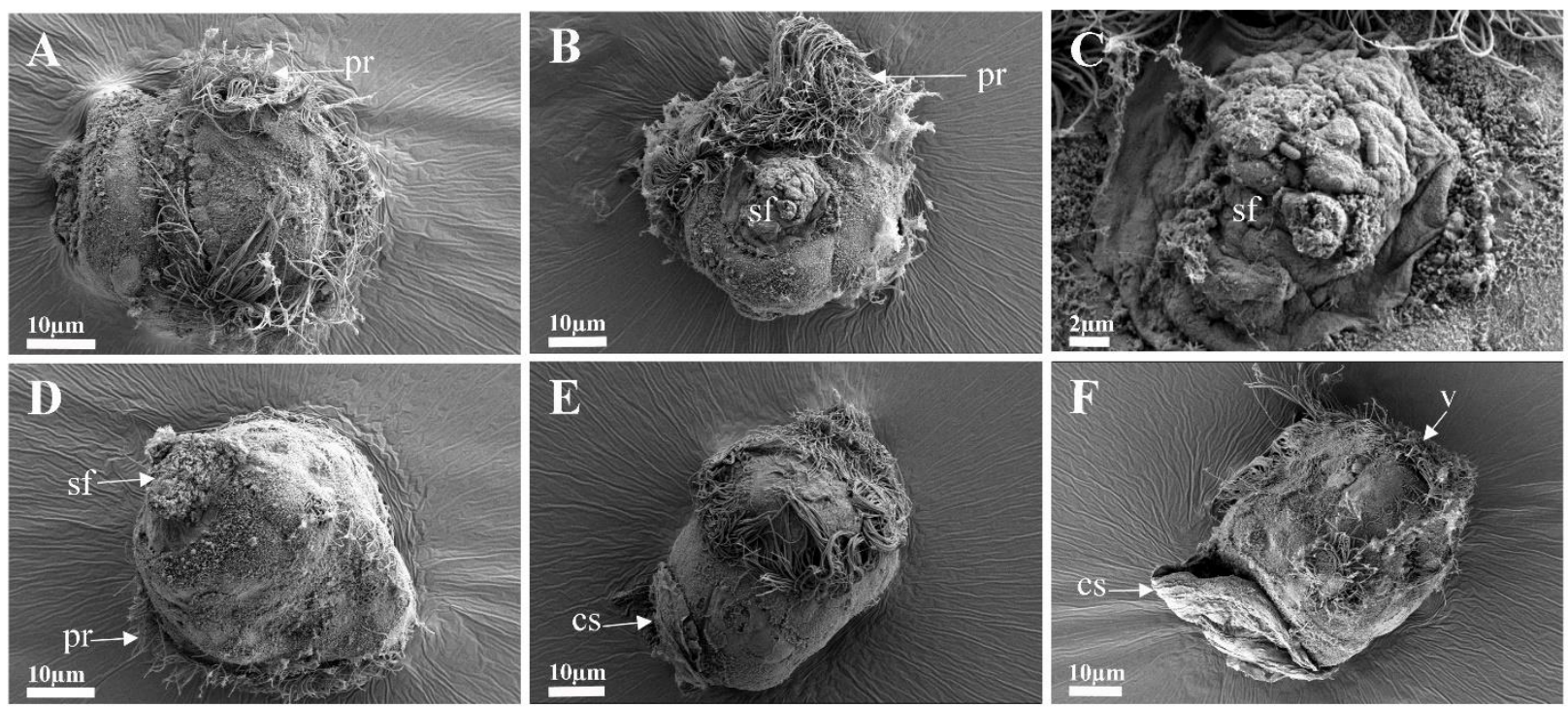

Fig. 2 Scanning electron micrographs of trochophores early veligers. A, Dorso-lateral view of trochophore showing prototroch ciliary band; B, lateral view showing tissue of shell field; C, higher magnification of shell field; D, ventro-lateral view showing developing shell field on lateral side of trochophore; E, dorso-lateral view of late trochophore showing first cup-shaped structure F, lateral view of early veliger showing extension of cup-shaped structure along the lateral side. Abbreviations: cs, cup-shaped structure; pr, prototroch ciliary band; sf, shell field; v, velum. 

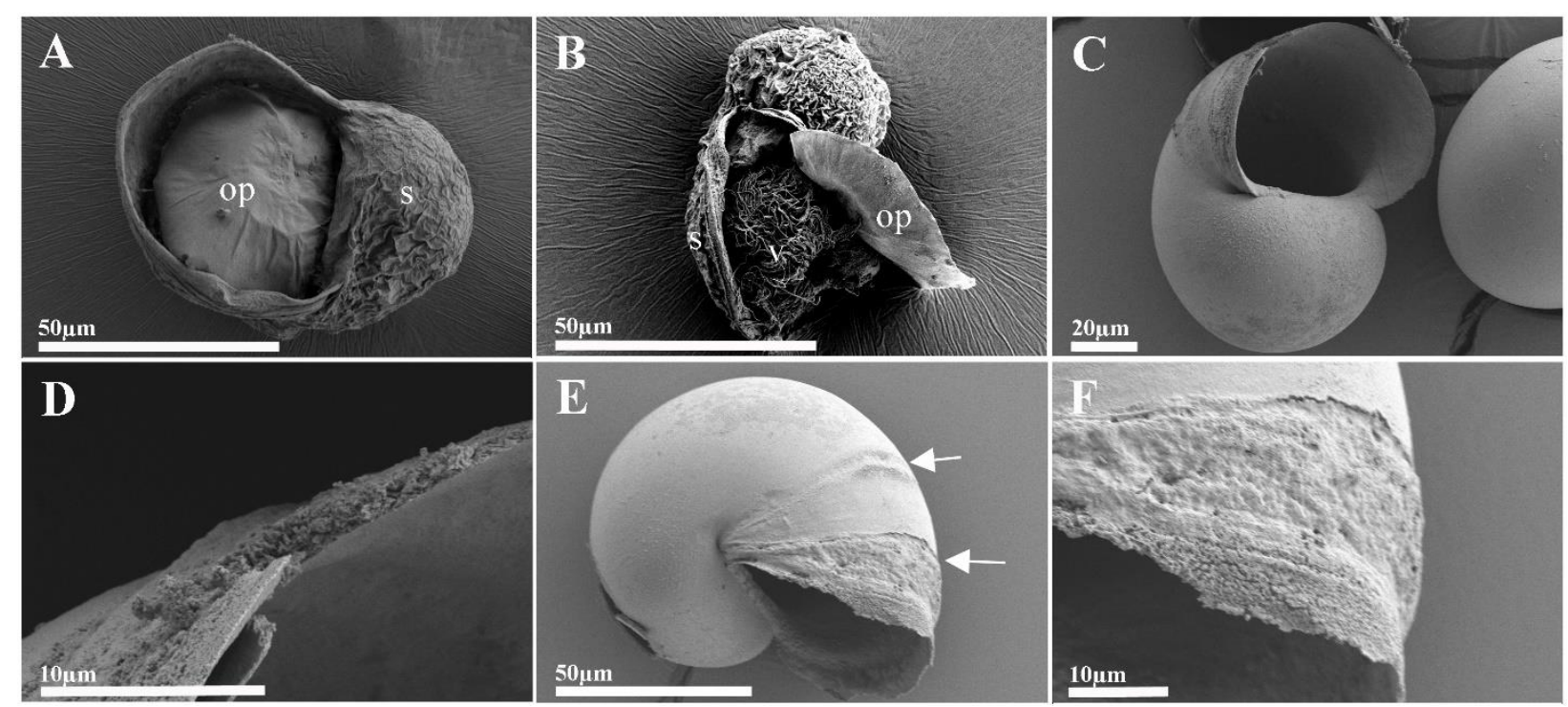

Fig. 3 Scanning electron micrographs of 1-2 week-old L. retroversa veliger. A, Ventral view of 1 week-old veliger with closed aperture; $\mathrm{B}$, lateral view of 1 week-old veliger showing velum inside the shell; C, Ventral view of 2 week-old shell; D, Cross section of growth margin; E, Lateral view of veliger shell showing two distinct calcification regions (white arrows); F, Higher magnification of growth margin. Abbreviations: op, operculum; s, shell; v, velum. 

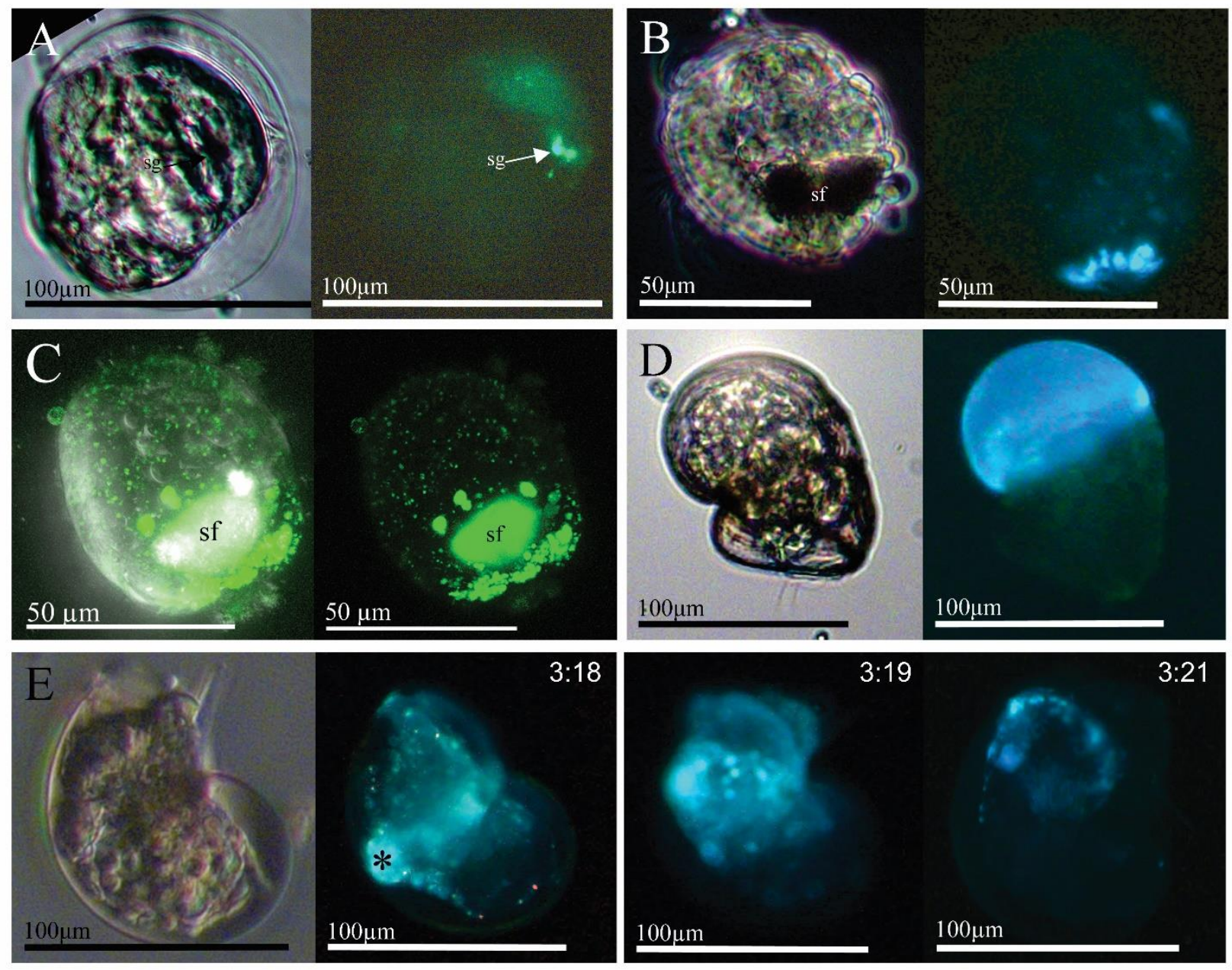

Fig. 4 Calcein-stained embryonic and larval stages of L. retroversa under normal light (left panels), fluorescent light (right panels), and with confocal laser scanning microscopy (both panels, C). A, late-stage gastrula with shell gland (1 d after $1 \mathrm{~h}$ in calcein); B, trochophore with shell field ( $3 \mathrm{~d}$ after $1 \mathrm{~h}$ in calcein); C, confocal micrographs under full light (left) and fluorescent light (right) showing live trochophore and shell field (40x) (2 d after $2 \mathrm{~h}$ in calcein); $\mathrm{D}$, larvae stained as a trochophore (1 $\mathrm{h}$ in calcein) then allowed to develop into a veliger (10 $\mathrm{d}$ after staining); E, Time lapse (time stamp upper right) of one week-old veliger ( $5 \mathrm{~d}$ after $1 \mathrm{~h}$ in calcein) showed staining of mantle (black asterisk) moving with the visceral mass inside the shell. Abbreviations: sf, shell field; sg, shell gland. 

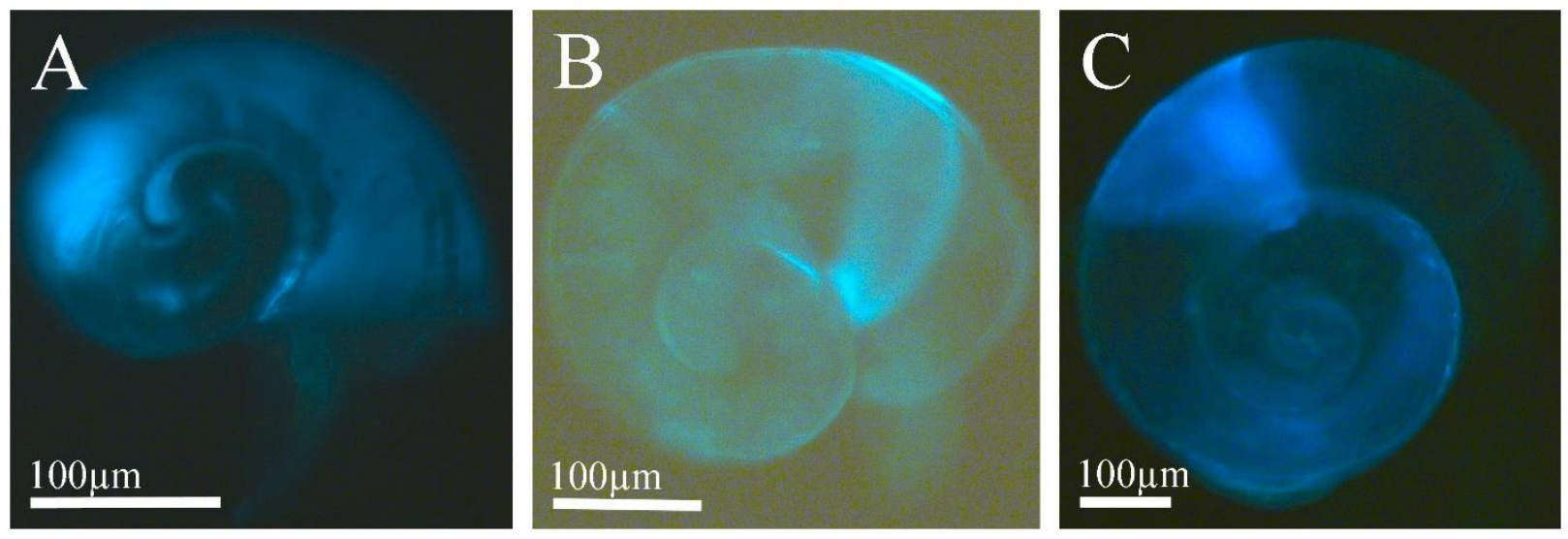

Fig. 5 Calcein-stained veliger and juvenile of $L$. retroversa under fluorescent light in ventral view. A, 3 week-old veliger (immediately after $1 \mathrm{~h}$ in calcein); B, 3 week-old veliger ( $8 \mathrm{~d}$ after 1 $\mathrm{h}$ in calcein); C, Juvenile (14 $\mathrm{d}$ after $1 \mathrm{~h}$ in calcein). 


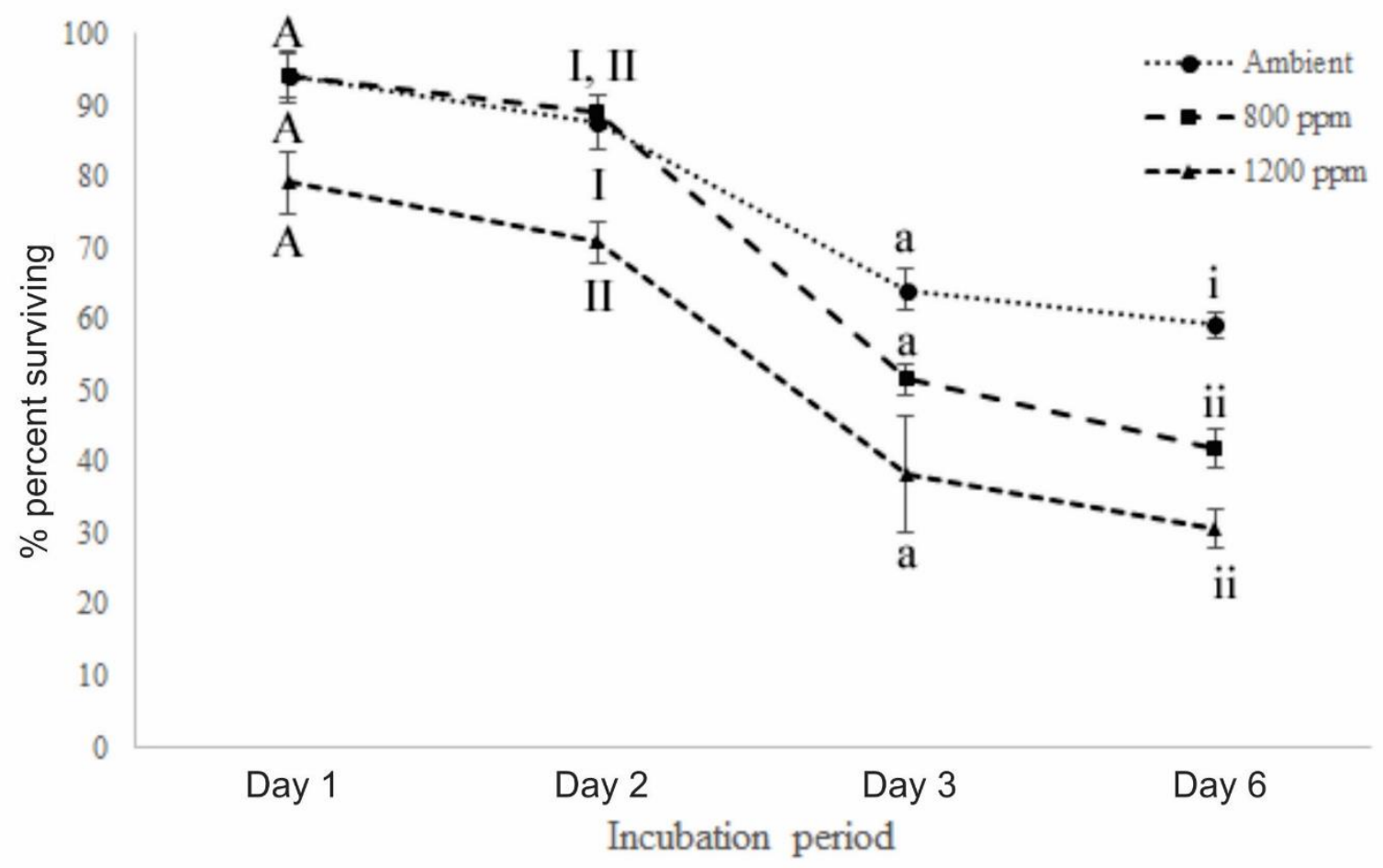

Fig. 6 Percent survival (mean $\pm \mathrm{SE}$ ) of $L$. retroversa embryos and over time with three different $\mathrm{CO}_{2}$ exposure conditions during Experiment 2 ( $n$ for each treatment and time point reported in Table 3). Letters and Roman numerals indicate significant differences between treatments at each individual day (Welch's one-way ANOVA with Dunnett's T3 post-hoc comparison, significance assessed at $P<0.05)$. 

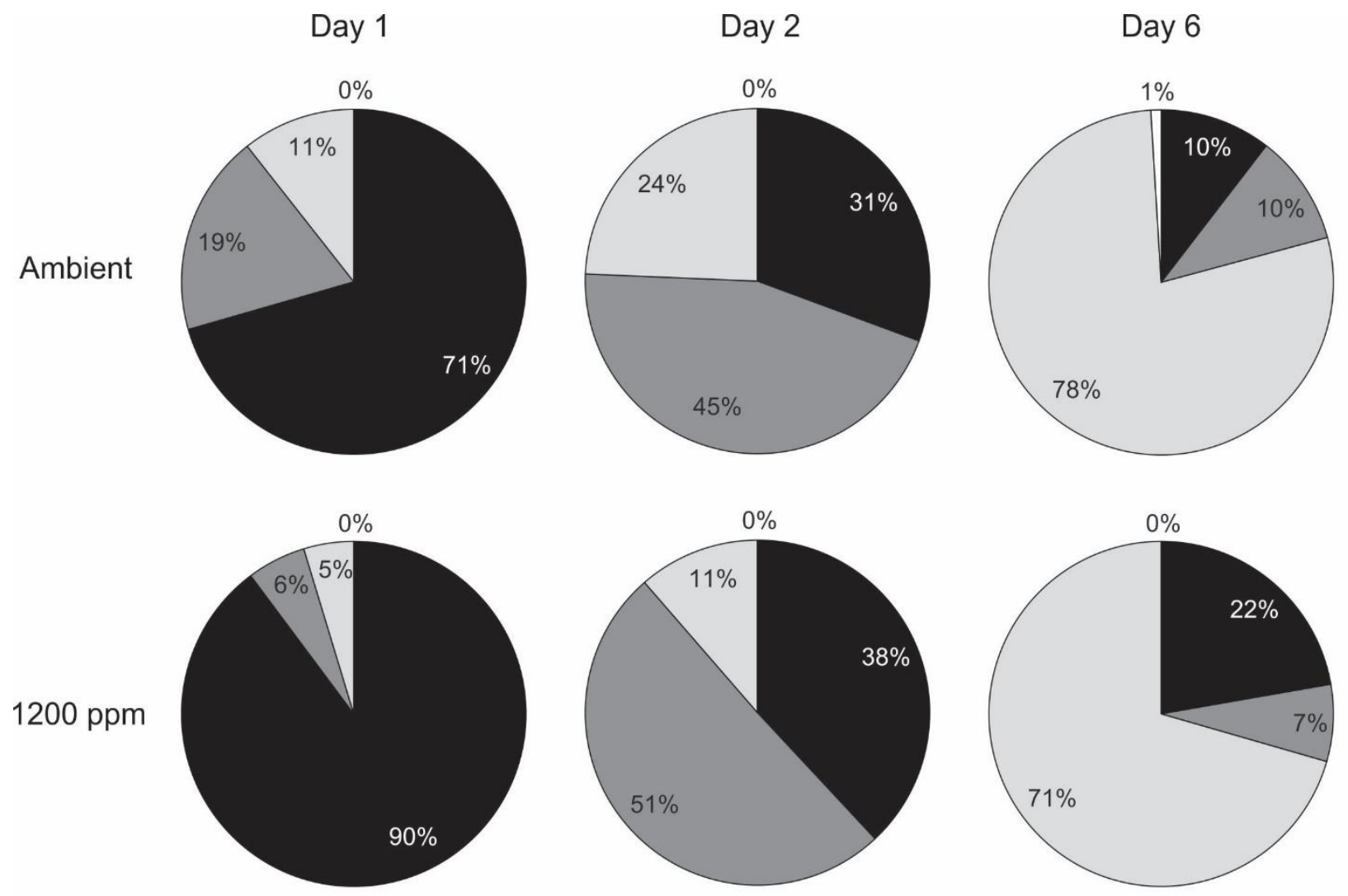

Fig. 7 Developmental progression of L. retroversa embryos and larvae from Experiment 2 on days 1, 2 and 6 of exposure to two different $\mathrm{CO}_{2}$ levels. Percentage of surviving larvae at early gastrula (non-motile; black), late gastrula (motile; dark grey), trochophore (light grey), and veliger (white) stage at each time point suggest a trend towards a developmental delay with a statistically significant difference on days 1 and 6 (Pearson Chi-Square test, significance assessed at $P<0.05$ ). 
Table 1 Observed timing of developmental stages of Limacina retroversa in laboratory culture at $8^{\circ} \mathrm{C}$.

\begin{tabular}{ll} 
Stage & Time \\
\hline spawning & $0 \mathrm{~h}$ \\
2-cell & $4 \mathrm{~h}$ \\
4-cell & $6 \mathrm{~h}$ \\
8-cell & $9 \mathrm{~h}$ \\
16-cell & $11 \mathrm{~h}$ \\
blastula & $16 \mathrm{~h}$ \\
gastrula & $24-72 \mathrm{~h}$ \\
hatching & $3 \mathrm{~d}$ \\
trochophore & $3-6 \mathrm{~d}$ \\
veliger & $6-7 \mathrm{~d}$ \\
juvenile & $1 \mathrm{mo}$ \\
reproductive adult & $3 \mathrm{mo}$ \\
life span & $6 \mathrm{mo}$
\end{tabular}


Table 2 Carbonate chemistry parameters including salinity, pH, DIC and TA were measured and used to calculate aragonite saturation state $(\Omega A r)$ and partial pressure of $\mathrm{CO}_{2}$ in the acidification experiments using the software CO2SYS. DIC and TA represent starting conditions, while $\mathrm{pH}$ and salinity were measured at each time point.

\section{Experiment 1}

\begin{tabular}{l|cccccc}
\hline \multicolumn{1}{c}{ Treatment } & Salinity & $\mathbf{p H} \pm$ SD & DIC & TA & SAr & pCO $_{2}$ \\
\hline Ambient & 33.5 & $8.02 \pm 0.018$ & 2021.2 & 2176.4 & 1.73 & 380.5 \\
$800 \mathrm{ppm}$ & 33.5 & $7.75 \pm 0.010$ & 2099.0 & 2161.7 & 0.98 & 753.5 \\
$1200 \mathrm{ppm}$ & 33.5 & $7.64 \pm 0.021$ & 2081.8 & missing & 0.73 & 993.2
\end{tabular}

Experiment 2

\begin{tabular}{l|cccccc}
\hline Treatment & Salinity & $\mathbf{p H} \pm$ SD & DIC & TA & (Ar & pCO2 \\
\hline Ambient & 33 & $8.01 \pm 0.012$ & 2068.9 & 2195.0 & 1.50 & 465.7 \\
$800 \mathrm{ppm}$ & 33 & $7.71 \pm 0.014$ & 2145.0 & 2193.6 & 0.90 & 854.9 \\
$1200 \mathrm{ppm}$ & 33 & $7.58 \pm 0.013$ & 2188.3 & 2191.5 & 0.63 & 1262.2
\end{tabular}


Table 3 Percent survival (mean $\pm \mathrm{SE}$ ) of $L$. retroversa embryos and larvae in two independent experiments, each with three $\mathrm{CO}_{2}$ exposure conditions. Each day (D) and exposure condition were represented by three independent replicates, except where only two replicates were available (indicated by shading). Results from Welch's one-way ANOVAs indicate the effect of OA treatment on mean percent survival of $L$. retroversa embryos and larvae.

\section{Experiment 1}

\begin{tabular}{l|lllll}
\hline Day & Ambient & $\mathbf{8 0 0} \mathbf{~ p p m}$ & $\mathbf{1 2 0 0} \mathbf{~ p p m}$ & $\mathbf{F}$ & Sig. \\
\hline D 1 & & & & & \\
D 2 & $95.0 \pm 3.8$ & $96.6 \pm 2.2$ & $55.8 \pm 9.8$ & 3.937 & $\mathbf{0 . 0 3 1}$ \\
D 3 & $56.6 \pm 18.0$ & $37.5 \pm 17.5$ & $42.5 \pm 18.4$ & 3.118 & 0.756 \\
D 6 & $71.6 \pm 12.0$ & $72.5 \pm 9.5$ & $45.0 \pm 5.7$ & 3.434 & 0.165 \\
\hline
\end{tabular}

Experiment 2

\begin{tabular}{l|lllll}
\hline & Ambient & $\mathbf{8 0 0} \mathbf{~ p p m}$ & $\mathbf{1 2 0 0} \mathbf{~ p p m}$ & $\mathbf{F}$ & Sig. \\
\hline D 1 & & & & & \\
D 2 & $94.2 \pm 3.6$ & $94.2 \pm 3.0$ & $79.2 \pm 4.4$ & 3.651 & 0.134 \\
D 3 & $87.5 \pm 3.8$ & $89.2 \pm 2.2$ & $70.8 \pm 3.0$ & 3.807 & $\mathbf{0 . 0 2 5}$ \\
D 6 & $64.2 \pm 3.0$ & $51.7 \pm 2.2$ & $38.3 \pm 8.2$ & 3.518 & 0.068 \\
& $59.2 \pm 1.7$ & $41.9 \pm 2.7$ & $30.7 \pm 2.7$ & 3.780 & $\mathbf{0 . 0 0 4}$
\end{tabular}




\title{
Electronic Supplementary Material for Marine Biology
}

Life cycle and early development of the thecosomatous pteropod Limacina retroversa in the Gulf of Maine, including the effect of elevated $\mathrm{CO}_{2}$ levels

\author{
Ali A. Thabet ${ }^{\mathrm{ab}}$, Amy E. Maas ${ }^{\mathrm{ac} *}$, Gareth L. Lawson ${ }^{\mathrm{a}}$ and Ann M. Tarrant ${ }^{\mathrm{a}}$ \\ a. Biology Department, Woods Hole Oceanographic Institution, Woods Hole, MA \\ 02543 \\ b. Zoology Dept., Faculty of Science, Al-Azhar University in Assiut, Assiut, Egypt. \\ c. Bermuda Institute of Ocean Sciences, St. George's GE01, Bermuda
}

*Corresponding Author, equal contribution with lead author

Email:amy.maas@bios.edu

Phone: 441-297-1880 x131

Culturing observations

Although there were no specific feeding experiments conducted as part of this study, it is presumed that Limacina retroversa individuals were eating at all life stages. It is implausible that eggs could have reached six months in the laboratory without sufficient nourishment during both veliger and adult stages. Surviving organisms appeared healthy and active throughout their six month captivity. Since the water was $1-\mu \mathrm{m}$ filtered prior to the addition of thecosomes and phytoplankton, there was nothing other than Rhodomonas lens, Isochrysis sp., clone T-Iso and Heterocapsa triquetra in the cultures, suggesting that these are appropriate food sources. The thecosomes (adults and juveniles) had dark guts, also supporting the feeding observation. We could not determine from these observations, however, whether it was multiple species being fed on or only one. Furthermore, we have no estimates of ingestion rate. We believe a large portion of the feeding was done via ciliary action as no mucous webs were directly observed. That does not mean they were never present. Typical adult behavior was to swim upwards in the water column then drift with parapodia extended downwards. Sometimes, in static culture, adults were seen to be neutrally buoyant or rising in the water column without swimming. No webs were superficially visible at this time, and although ciliary action and wing position could possibly explain the phenomenon, we did no tests to determine whether this was the cause of the observed behavior. Apparently healthy individuals were also seen resting on the bottom of the jar with parapodia extended. Mating and spawning were not directly observed during the culture period. 
Table ESM 1 Average $( \pm \mathrm{SD})$ dimensions $(\mu \mathrm{m})$ and area $\left(\mu \mathrm{m}^{2}\right)$ of L. retroversa egg capsule, embryos and trochophores, as well as veliger and juvenile shells $(\mu \mathrm{m})$.

\begin{tabular}{|c|c|c|c|c|c|c|c|}
\hline \multirow[t]{2}{*}{ Stage } & \multirow[t]{2}{*}{$\#$} & \multicolumn{3}{|c|}{ Egg Capsule } & \multicolumn{3}{|c|}{ Embryo } \\
\hline & & Length & Width & Area & Length & Width & Area \\
\hline 1-cell & 6 & $116 \pm 13$ & $98 \pm 9$ & $8777 \pm 1457$ & $81 \pm 5$ & $80 \pm 5$ & $5029 \pm 629$ \\
\hline 2-cell & 4 & $117 \pm 3$ & $94 \pm 5$ & $8594 \pm 80$ & $100 \pm 6$ & $68 \pm 3$ & $5620 \pm 380$ \\
\hline 4-cell & 13 & $116 \pm 7$ & $97 \pm 5$ & $8503 \pm 736$ & $104 \pm 8$ & $86 \pm 6$ & $5982 \pm 704$ \\
\hline 8-cell & 4 & $120 \pm 11$ & $94 \pm 5$ & $8700 \pm 679$ & $102 \pm 10$ & $74 \pm 5$ & $5649 \pm 1134$ \\
\hline blastula & 10 & $115 \pm 4$ & $99 \pm 5$ & $8777 \pm 571$ & $90 \pm 3$ & $81 \pm 5$ & $5606 \pm 618$ \\
\hline \multirow[t]{2}{*}{ gastrula } & 15 & $117 \pm 7$ & $93 \pm 7$ & $8304 \pm 803$ & $80 \pm 7$ & $72 \pm 6$ & $4411 \pm 765$ \\
\hline & & Length & Width & Area & \multicolumn{3}{|c|}{ Shell gland } \\
\hline trochophore & 20 & $77 \pm 7$ & $63 \pm 5$ & $4029 \pm 607$ & $850 \pm 251$ & & \\
\hline
\end{tabular}

\begin{tabular}{lllll} 
& & $\begin{array}{l}\text { Shell } \\
\text { diameter }\end{array}$ & Shell height & Shell area \\
\hline veliger (one week) & 10 & $103 \pm 9$ & $81 \pm 8$ & $7357 \pm 1245$ \\
veliger (two week) & 15 & $98 \pm 6$ & $73 \pm 6$ & $5985 \pm 622$ \\
& & & Shell diameter \\
& & \# of whorls & \multicolumn{2}{l}{} \\
\hline juvenile & 15 & $3.2 \pm 0.37$ & $556 \pm 88$
\end{tabular}




\section{Experiment 1}

\begin{tabular}{|c|c|c|c|c|c|c|c|c|c|c|c|c|c|c|}
\hline \multirow{2}{*}{ Day Stages } & \multicolumn{5}{|c|}{ Ambient } & \multicolumn{4}{|c|}{800 ppm } & \multicolumn{4}{|c|}{1200 ppm } & \multirow{2}{*}{$\begin{array}{c}\text { Stats } \\
\text { Sig. }\end{array}$} \\
\hline & Gast. & $\begin{array}{l}\text { Late } \\
\text { Gast. }\end{array}$ & Troch. & V. & Dead & Gast. & $\begin{array}{l}\text { Late } \\
\text { Gast. }\end{array}$ & Troch. & Dead & Gast. & $\begin{array}{l}\text { Late } \\
\text { Gast. }\end{array}$ & Troch. & Dead & \\
\hline D 1 & $\begin{array}{l}95.8 \pm \\
3.0\end{array}$ & -- & -- & -- & $\begin{array}{l}5.0 \pm \\
3.8\end{array}$ & $\begin{array}{l}96.7 \pm \\
2.2\end{array}$ & -- & -- & $\begin{array}{l}3.3 \pm \\
2.2\end{array}$ & $\begin{array}{l}57.5 \pm \\
8.8\end{array}$ & -- & -- & $\begin{array}{l}44.2 \pm \\
9.8\end{array}$ & -- \\
\hline D 2 & $\begin{array}{l}65.0 \pm \\
16.6\end{array}$ & -- & -- & -- & $\begin{array}{l}43.3 \pm \\
18.0\end{array}$ & $\begin{array}{l}37.5 \pm \\
17.5\end{array}$ & -- & -- & $\begin{array}{l}62.5 \pm \\
17.5\end{array}$ & $\begin{array}{l}42.5 \pm \\
18.4\end{array}$ & -- & -- & $\begin{array}{l}57.5 \pm \\
18.4\end{array}$ & -- \\
\hline D 3 & $\begin{array}{l}51.7 \pm \\
2.2\end{array}$ & $\begin{array}{l}13.3 \pm \\
2.2\end{array}$ & $\begin{array}{l}6.7 \pm \\
4.4\end{array}$ & -- & $\begin{array}{l}28.3 \pm \\
12.0\end{array}$ & $\begin{array}{l}52.5 \pm \\
5.2\end{array}$ & $\begin{array}{l}10.8 \pm \\
0.8\end{array}$ & $\begin{array}{l}0.8 \pm \\
0.8\end{array}$ & $\begin{array}{l}27.5 \pm \\
9.5\end{array}$ & $\begin{array}{l}40.0 \pm \\
2.9\end{array}$ & $\begin{array}{l}5.0 \pm \\
2.9\end{array}$ & -- & $\begin{array}{l}55.0 \pm \\
5.8\end{array}$ & 0.020 \\
\hline D 6 & -- & $\begin{array}{l}6.0 \pm \\
1.0\end{array}$ & $\begin{array}{l}21.3 \pm \\
2.9\end{array}$ & -- & $\begin{array}{l}72.8 \pm \\
3.9\end{array}$ & -- & $\begin{array}{l}4.4 \pm \\
4.4\end{array}$ & $\begin{array}{l}31.1 \pm \\
0.8\end{array}$ & $\begin{array}{l}64.4 \pm \\
3.6\end{array}$ & -- & $\begin{array}{l}2.1 \pm \\
0.8\end{array}$ & $\begin{array}{l}0.7 \pm \\
0.4\end{array}$ & $\begin{array}{l}97.2 \pm \\
0.6\end{array}$ & $>0.001$ \\
\hline
\end{tabular}

Experiment 2

\begin{tabular}{|c|c|c|c|c|c|c|c|c|c|c|c|c|c|c|}
\hline \multirow{2}{*}{$\underbrace{\text { Treatment }}_{\text {Day }}$} & \multicolumn{5}{|c|}{ Ambient } & \multicolumn{4}{|c|}{800 ppm } & \multicolumn{4}{|c|}{1200 ppm } & \multirow{2}{*}{$\begin{array}{c}\text { Stats } \\
\text { Sig. }\end{array}$} \\
\hline & Gast. & $\begin{array}{l}\text { Late } \\
\text { Gast. }\end{array}$ & Troch. & V. & Dead & Gast. & $\begin{array}{l}\text { Late } \\
\text { Gast. }\end{array}$ & Troch. & Dead & Gast. & $\begin{array}{l}\text { Late } \\
\text { Gast. }\end{array}$ & Troch. & Dead & \\
\hline D 1 & $\begin{array}{l}66.7 \pm \\
5.8\end{array}$ & $\begin{array}{l}17.5 \pm \\
2.5\end{array}$ & $\begin{array}{l}10.0 \pm \\
2.5\end{array}$ & -- & $\begin{array}{l}5.8 \pm \\
3.6\end{array}$ & $\begin{array}{l}70.0 \pm \\
3.8\end{array}$ & $\begin{array}{l}14.7 \pm \\
3.6\end{array}$ & $\begin{array}{l}5.8 \pm \\
3.6\end{array}$ & $\begin{array}{l}5.8 \pm \\
3.0\end{array}$ & $\begin{array}{l}62.5 \pm \\
2.5\end{array}$ & $\begin{array}{l}4.2 \pm \\
2.2\end{array}$ & $\begin{array}{l}3.3 \pm \\
0.8\end{array}$ & $\begin{array}{l}20.8 \pm \\
4.4\end{array}$ & 0.035 \\
\hline D 2 & $\begin{array}{l}23.3 \pm \\
8.8\end{array}$ & $\begin{array}{l}38.3 \pm \\
10.2\end{array}$ & $\begin{array}{l}20.8 \pm \\
6.7\end{array}$ & -- & $\begin{array}{l}12.5 \pm \\
3.8\end{array}$ & $\begin{array}{l}22.5 \pm \\
1.4\end{array}$ & $\begin{array}{l}51.7 \pm \\
3.0\end{array}$ & $\begin{array}{l}16.7 \pm \\
3.3\end{array}$ & $\begin{array}{l}10.8 \pm \\
2.2\end{array}$ & $\begin{array}{l}25 \pm \\
2.5\end{array}$ & $\begin{array}{l}34.2 \pm \\
5.8\end{array}$ & $\begin{array}{l}7.5 \pm \\
0\end{array}$ & $\begin{array}{l}29.2 \pm \\
3.0\end{array}$ & 0.080 \\
\hline D 3 & $\begin{array}{l}6.7 \pm \\
3.0\end{array}$ & $\begin{array}{l}35.8 \pm \\
7.3\end{array}$ & $\begin{array}{l}25.0 \pm \\
2.9\end{array}$ & -- & $\begin{array}{l}35.8 \pm \\
3 .\end{array}$ & $\begin{array}{l}6.7 \pm \\
1.7\end{array}$ & $\begin{array}{l}30.0 \pm \\
5.2\end{array}$ & $\begin{array}{l}15.0 \pm \\
4.3\end{array}$ & $\begin{array}{l}48.3 \pm \\
2.2\end{array}$ & $\begin{array}{l}2.5 \pm \\
1.4\end{array}$ & $\begin{array}{l}21.7 \pm \\
3.0\end{array}$ & $\begin{array}{l}12.5 \pm \\
5.2\end{array}$ & $\begin{array}{l}61.7 \pm \\
8.2\end{array}$ & 0.761 \\
\hline D 6 & $\begin{array}{l}6.0 \pm \\
1.7\end{array}$ & $\begin{array}{l}6.0 \pm \\
0.6\end{array}$ & $\begin{array}{l}45.3 \pm \\
3.1\end{array}$ & $\begin{array}{l}1.0 \pm \\
0.1\end{array}$ & $\begin{array}{l}40.8 \pm \\
1.7\end{array}$ & $\begin{array}{l}0.8 \pm \\
0.6\end{array}$ & $\begin{array}{l}1.9 \pm \\
0.7\end{array}$ & $\begin{array}{l}39.2 \pm \\
4.0\end{array}$ & $\begin{array}{l}58.1 \pm \\
2.7\end{array}$ & $\begin{array}{l}6.9 \pm \\
2.1\end{array}$ & $\begin{array}{l}2.4 \pm \\
1.1\end{array}$ & $\begin{array}{l}21.5 \pm \\
2.2\end{array}$ & $\begin{array}{l}69.3 \pm \\
2.7\end{array}$ & $>0.001$ \\
\hline
\end{tabular}

Table ESM 2 Distribution of L. retroversa (percentage, mean \pm SE) developmental stages during two independent experiments, each with three $\mathrm{CO}_{2}$ exposure conditions. Each day (D) and exposure condition were represented by three independent replicates, except where only two replicates were available (indicated by shading). At the start of the experiment all individuals were in the gastrula stage (Gast.) and over time they transitioned to late gastrula (Late Gast.) characterized by shell gland formation, then to a trochophore (Troch.) and occasionally to a veliger (V.). The mortality during the experiment is documented as the percentage of dead individuals (Dead). Results from Pearson Chi-Square (Sig.) tested for the effect of OA treatment on developmental stage distribution for $L$. troversa embryos and larvae, excluding the dead individuals and combining trochophore and veliger stages into one classification. 